\title{
Caracterización morfo-tipológica de los barrios obreros públicos en la ciudad de Guayaquil (1937-1948)
}

\author{
Juan Carlos Bamba Vicente ${ }^{1}$ | Florencio Compte Guerreo ${ }^{2}$ | Ximena Vaca Romero ${ }^{3}$
}

Recibido: 11-05-2020 | en su versión final: 02-10-2020

Resumen

\begin{abstract}
El objetivo fundamental de la investigación es describir y caracterizar los barrios obreros producidos por instituciones públicas en la ciudad Guayaquil entre 1937, año en que inicia su acción la Caja del Seguro Social, y 1948, cuando en Ecuador finaliza el periodo de crisis económica y política y se produce un cambio en el modelo de urbanización hacia la ciudadela. Estos barrios representan los orígenes de la arquitectura y el urbanismo moderno en Guayaquil porque suponen una revolución de las formas urbanas y los tipos edificatorios en relación a los espacios de transición entre la calle y la casa. Los proyectos afrontan el problema de la vivienda considerando nuevos estándares higiénicos, optimizando la célula habitacional, estandarizando los sistemas constructivos e incorporando servicios de uso comunitario a escala de barrio La investigación es cualitativa y se centra en la relación entre la organización espacial y las prácticas sociales e incorpora ciertos valores cuantitativos que permiten un análisis comparativo en base a variables comunes. Se aborda el estudio con el método analítico-sintético que consiste en la cualificación y caracterización de los rasgos determinantes de cada caso desde su contextualización histórica y geográfica hasta un análisis a diferentes escalas: el conjunto urbano, la agrupación de viviendas y los tipos de vivienda. La arquitectura de vivienda analizada transforma radicalmente la cultura del habitar de la sociedad guayaquileña y el afán de esta investigación es valorizar estos barrios como patrimonio cultural.
\end{abstract}

Palabras clave: morfología urbana; tipología edificatoria; vivienda para empleados; arquitectura moderna

Citación

\section{Morpho-Typological Characterization of the Public Working Class Neighborhoods in the City of Guayaquil (1937-1948)}

Abstract

\begin{abstract}
The fundamental objective of the research is to describe and characterize the working class neighborhoods produced by public institutions in the city of Guayaquil between 1937, the year in which the Social Security Fund began its action, and 1948, when in Ecuador the period of economic crisis and political and there is a change in the urbanization model towards the citadel. These neighborhoods represent the origins of modern architecture and urban planning in Guayaquil because they represent a revolution in urban forms and building types in relation to the transition spaces between the street and the house. The projects tackle the problem of housing considering new hygiene standards, optimizing the housing cell, standardizing construction systems and incorporating services for community use at the neighborhood level. The research is qualitative and focuses on the relationship between spatial organization and social practices and incorporates certain quantitative values that allow a comparative analysis based on common variables. The study is approached with the analytical-synthetic method that consists of the qualification and characterization of the determining features of each case, from its historical and geographical context to an analysis at different scales: the urban complex, the group of dwellings and the types of dwelling. The analyzed housing architecture radically transforms the culture of living in Guayaquil society and the aim of this research is to value these neighborhoods as cultural heritage.
\end{abstract}

Keywords: urban morphology; building typology; employee housing; modern architecture

Doctor, Universidad Católica de Santiago de Guayaquil (ORCID: 0000-0001-6395-1565), 2 Doctor, Universidad Católica de Santiago de Guayaquil (ORCID: 0000-0002-4205-343X), ${ }^{3}$ Arquitecta, Universidad Católica de Cuenca (ORCID: 0000-0003-0047-7768). Correo de contacto: jcarlosbamba@gmail.com 


\section{Un método de investigación multiescalar para la arquitectura de vivienda}

El artículo se enfoca en entender las lógicas de crecimiento urbano mediante la caracterización morfo-tipológica - morfología urbana y tipos edificatorios- de los barrios obreros producidos por instituciones públicas después del Gran Incendio para la reconstrucción de la ciudad de Guayaquil.

El análisis de la evolución de los casos en el periodo de estudio planteado permite entender la realidad de la ciudad en un determinado contexto social, económico y político. El estudio comparado de los barrios explica el proceso de urbanización y modernización de la ciudad: la introducción de la arquitectura de vivienda moderna en Guayaquil a través de los barrios obreros con la incorporación de principios higienistas como la implementación de retiros, patios y pasajes, y criterios de estandarización y racionalización de las viviendas. El producto analizado es una respuesta dialéctica entre la vivienda popular y la vivienda racional cuyas referencias las encontramos en Europa y Norteamérica, pero también en otros países de Latinoamérica en los que las arquitecturas de vivienda moderna llegaron antes que a Guayaquil.

\section{Antecedentes históricos de los barrios obreros de Guayaquil}

\subsection{El problema del alojamiento y la vivienda para empleados}

En los inicios del proceso independentista del Ecuador hacia 1820, con las nuevas vinculaciones comerciales con Inglaterra y Francia, a través de la exportación del cacao, el crecimiento poblacional de la ciudad de Guayaquil se vuelve acelerado hasta sobrepasar demográficamente a la población de Quito a finales del siglo XIX; ${ }^{1}$ situación que se mantiene hasta el día de hoy. Entre 1880 y 1930 se produce un notable "incremento de la producción cacaotera", lo que los historiadores han denominado el "Segundo boom cacaotero", hecho que no hizo más que intensificar el crecimiento demográfico de la ciudad de Guayaquil (Rojas y Villavicencio, 1988, p. 21).

Este fenómeno de crecimiento poblacional explosivo introduce en la forma urbana un proceso de densificación más que de dispersión. ${ }^{2}$ El crecimiento poblacional contrasta con otro fenómeno que acelera la pérdida de gran parte de la infraestructura productiva y del patrimonio construido de la ciudad: el llamado "Gran Incendio" del 5 y 6 de octubre de 1896 (Lee y Compte, 1992, p. 50). Este incendio destruye casi la mitad de la urbe, y con ello, fragmentos irreparables de su historia urbana. La ciudad pierde de esta forma gran parte de su memoria, por lo que debe reconstruirse sin mirar al pasado y bajo las premisas de una arquitectura y urbanismo que la catapulten a un futuro de progreso y modernización (Figura 1).

La "crisis cacaotera" de 1922, originada por la pérdida de mercados internacionales y la afectación en las plantaciones, cuyas consecuencias inmediatas son "el descenso de las actividades comerciales y bancarias y la quiebra de ciertas empresas” (Rojas y Villavicencio, 1988, p. 68), unidas al posterior "crack" mundial de 1929, produce en Ecuador y, particularmente, en la ciudad de Guayaquil, un periodo de inestabilidad económica y política que se prolonga hasta fines de los años cuarenta; este proceso se traduce en la pauperización de las clases populares, la tugurización de

\footnotetext{
1 Para 1892, Guayaquil es la ciudad con la mayor población del país, superando a Quito. En 1899, su población ascendía a 60.000 habitantes, y su extensión en hectáreas pasó de 224 en 1886 a 460 en 1903. Su crecimiento demográfico entre 1905 y 1942 es del $1,7 \%$.

2 De unos 70.000 habitantes a comienzos del siglo XX, llega casi a 120.000 en 1930. La ciudad crece de 460 a 590 hectáreas, lo que significa una densidad de casi 200 habitantes por hectáreas.
}

ACE, 15 (45) CC BY-ND 3.0 ES | UPC Barcelona, España | Caracterización morfo-tipológica de los barrios obreros públicos en la ciudad de Guayaquil (1937-1948). DOI: http://dx.doi.org/10.5821/ace.15.45.9311 
Las manzanas del centro de la ciudad y la ocupación de terrenos periféricos anegadizos por parte de migrantes de las zonas rurales (Cueva, 1973). Guayaquil, con estos antecedentes, se enfrenta en ese momento al inexorable problema del alojamiento de las clases populares provenientes del campo: el "problema de la vivienda". ${ }^{3}$

Figura 1. Plano de Guayaquil después del Gran Incendio ocurrido el 6 de octubre de 1896
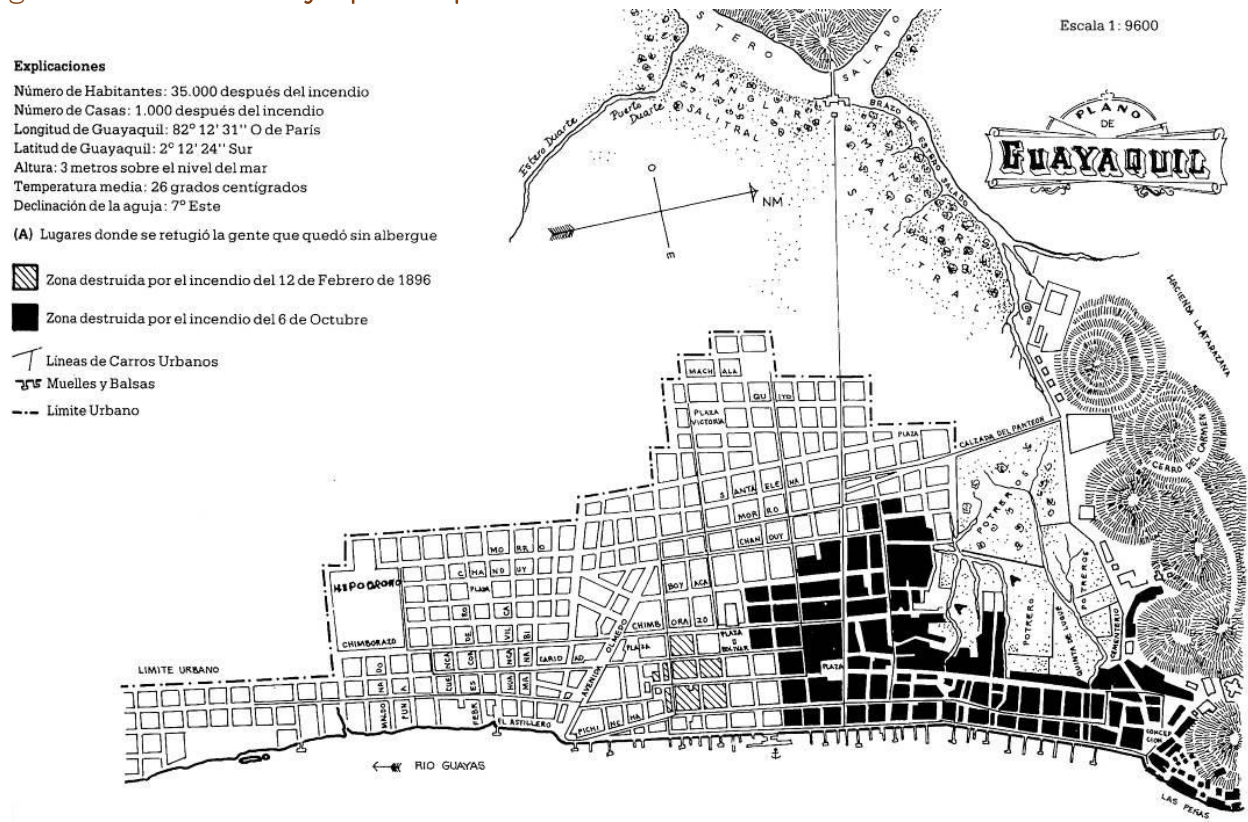

Fuente: Rojas y Villavicencio, 1988.

En el siglo XIX, Edwin Chadwick (1843) sacude la perspectiva de la sociedad de Gran Bretaña cuando realiza un informe detallado de las lamentables condiciones de vida de la población obrera de la ciudad industrial. Este informe dio pie a la primera Ley de Salud Pública inglesa en 1948, que nace como un intento de equidad social y mejoramiento de la salud urbana. La investigación constituye un antecedente fundamental de los criterios higienistas del urbanismo moderno respecto a la vivienda y la ciudad. Posteriormente, entre 1872 y 1873, con el escrito de Friedrich Engels (1872), Contribución al problema de la vivienda, ${ }^{4}$ se sientan en Europa las bases científicas sobre el "problema de la vivienda" en el que se desmitifican las concepciones burguesas al respecto, y se puntualizan los motivos de las condiciones de vida de los trabajadores y la salida revolucionaria como única y verdadera solución a esta realidad. Desde este momento se empieza a pensar, según Robin Evans (1997, p. 113), que la arquitectura de vivienda puede ser la solución "contra los males gemelos del vicio y la salud enferma de las ciudades".

Algunos años después, en Latinoamérica, influidos por el texto de Engels, los ideales higienistas ven en la vida de los "tugurios" 5 soluciones habitacionales precarias que constituyen una fuente inagotable de enfermedades y promiscuidad. Es de vital importancia en este sentido, la influencia

\footnotetext{
${ }^{3}$ Las migraciones internas generadas por el éxodo del campo a la ciudad, incrementan exponencialmente la población de Guayaquil; en el período comprendido entre 1929 y 1934 la tasa de crecimiento poblacional de la ciudad llega a un ritmo anual del 5,22\%, provocando que la demanda de vivienda supere la escasa oferta habitacional existente.

${ }^{4}$ Escrito por Engels de mayo 1872 a enero de 1873. Publicado por vez primera en el periódico Volkstaat, números. 51-53, 103 y 104, del 26 y 29 de junio, 3 de julio, 25 y 28 de diciembre de 1872; números. 2, 3, 12, 13 , 15 y 16 del 4 y 8 de enero, 8 , 12, 19 y 22 de febrero de 1873 y en tres sobretiros aparte, publicados en Leipzig en 1872 y 1873.

${ }^{5}$ La tugurización y hacinamiento en las viviendas de los centros de las grandes ciudades latinoamericanas se convirtió en un grave problema habitacional en la primera mitad del siglo XX; estas situaciones urbanas tienen diferentes nombres según los países: "conventillos" en Chile y Argentina, "ciudadelas" en Cuba, "corticos" en Brasil, y "tugurios" en Ecuador.
} 
de los Congresos Panamericanos de Arquitectos en los que se anuncia el "problema de la vivienda económica", también conocido con el término de "casas baratas", y donde se prepara el terreno para la generación de toda la maquinaría de instituciones, políticas y programas promovidos por los estados latinoamericanos. En el primer congreso, realizado en Montevideo en 1920, participaron Argentina, Bolivia, Brasil, Colombia, Cuba, Chile, Estados Unidos, Paraguay, Uruguay y Ecuador.

La creación de instituciones públicas en Latinoamérica orientadas a la producción de vivienda económica surge de manera desigual, pero con los mismos fines, en cada uno de los países. Los pioneros son Argentina, con la creación de la Comisión Nacional de Casas Baratas (1915); Venezuela con la fundación del Banco Obrero (1928); y México como parte de las prestaciones de la Dirección General de Pensiones Civiles y de Retiro (1938). Pero realmente es a partir de la Segunda Guerra Mundial, con la agudización de la crisis económica a nivel mundial y con el incremento de los procesos de migración del campo a la ciudad, cuando se produce el verdadero auge de la intervención directa del Estado con el desarrollo de programas masivos de vivienda para empleados y obreros que beneficiaron a la larga a los sectores socioeconómicos medios de la población (Pradilla, 1983).

Uno de los momentos cruciales del problema de la vivienda en Latinoamérica es el Primer Congreso Panamericano de la Vivienda Popular que se celebra en Buenos Aires en 1939, y en el que participa una delegación del Ecuador junto a los representantes de los demás países. En este congreso se analiza el problema del alojamiento desde un punto de vista teórico y práctico, siendo uno de los temas principales que se discutieron la definición de "lo popular" en relación a la vivienda como objeto material y de representación social, y de "los ingresos de las familias trabajadoras para acceder a una vivienda económica, sobre el papel de los bancos hipotecarios, las cooperativas y cajas de ahorro" y "sobre la construcción por acción combinada del estado con el capital privado” (Gutiérrez, Tartarini, Stagno, 2007, p. 18). En las conclusiones del congreso se sugiere la creación de instituciones de vivienda popular en cada uno de los países de Latinoamérica, además de un Comité Interamericano de la Vivienda Popular, con el objetivo de intercambiar experiencias y prácticas que se fueran desarrollando en los países involucrados.

Las grandes ciudades de Latinoamérica fueron un laboratorio continuo de pruebas para los ideales modernos sobre la ciudad y la arquitectura de vivienda sobre todo entre 1930 y 1960. La continuidad de los debates de los años treinta en Europa, la idea de la "vivienda mínima" del II CIAM (Aymonino, 1973, p. 90) y el urbanismo moderno ortodoxo expresado en La Carta de Atenas del IV CIAM, no se produce en el continente europeo después de la Segunda Guerra Mundial, sino en Latinoamérica. Los modelos utópicos que no se pudieron realizar en Europa debido a la guerra, se materializaron en Latinoamérica en una especie de gran laboratorio del habitar moderno para las clases medias: lo que se conoció como la "vivienda para empleados" (Romero, 2010, p. 355).

Los Estados latinoamericanos desarrollan políticas, más o menos eficaces, de construcción de viviendas, calificadas generalmente como "para empleados privados", con lo que se quiere indicar exactamente que no eran barrios populares. La diferencia principal entre Europa y Latinoamérica en temas de vivienda es que, por ejemplo, en Viena, se optó por una política de alquiler para la clase obrera, mientras que en los países latinoamericanos la preocupación fue "convertir en propietarios a la clase media" (Sambricio, 2012, p. 37). A continuación, se describe el origen de los barrios obreros en Guayaquil como el inicio de los programas de viviendas para empleados en la ciudad.

\subsection{El origen de los barrios en la ciudad de Guayaquil}

A finales del siglo XVIII, la ciudad de Guayaquil estaba dividida en seis barrios: Ciudad Nueva, Ciudad Vieja, barrio del Puente, barrio del Bajo, barrio del Astillero y barrio de Las Peñas. Estos barrios

ACE, 15 (4.5) CC BY-ND 3.0 ES | UPC Barcelona, España | Caracterización morfo-tipológica de los barrios obreros públicos en la ciudad de Guayaquil (1937-1948). DOI: http://dx.doi.org/10.5821/ace.15.45.9311 
representan verdaderas entidades sociales y económicas, cuya estratificación se materializa espacialmente en la "jerarquización lineal" de las manzanas desde el malecón del río Guayas hacia el interior: desde los comercios y servicios exclusivos de la burguesía a las actividades de los barrios de las clases bajas. La segregación socioespacial es inherente al concepto de barrio en Guayaquil, en este caso, mediante la estratificación progresiva de franjas paralelas al río (Bock, 1992) (Figura 2).

Figura 2. Estratificación de los tipos de viviendas en función de su asignación

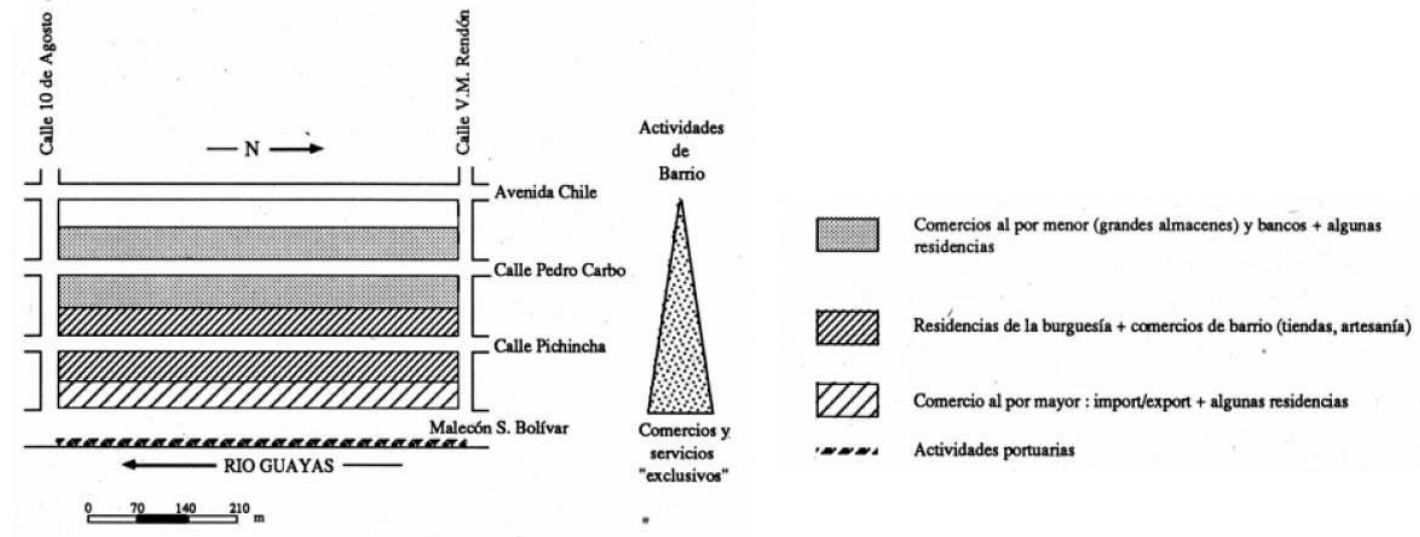

Fuente: Sophie Bock, 1992.

Si bien la noción de barrio ha existido siempre en Guayaquil, el crecimiento urbano acelerado a partir de la década de 1930 da lugar a la formación de nuevos barrios fácilmente identificables. Durante los años treinta se pueden identificar dos tipos de barrios en Guayaquil: los barrios multifuncionales -en general históricos- y los barrios monofuncionales - exclusivamente residenciales-. El criterio funcional — dependiente de una previa identificación social- se acompaña con una distinción a nivel de los límites externos, definiéndose, de esta forma, el barrio como unidad de segregación socioespacial. Este fenómeno evoluciona de una segregación interna en las viviendas en el siglo XIX hacia una segregación espacial por barrios diferenciados en el siglo XX. La categorización de los barrios en Guayaquil se establece según una serie de factores que se repiten a lo largo de la historia como la clasificación por estrato social a partir del costo del suelo y por su ubicación geográfica (Solano y Villacrés, 2011).

En el límite del sur de la ciudad se construye en la década de 1920 la "primera urbanización planificada” del Ecuador: el Barrio de El Centenario (Rojas y Villavicencio, 1988, p. 33). Este proyecto constituye el primer barrio proyectado como una agrupación de vecinos que pueden compartir beneficios comunes a nivel de servicios e infraestructura. A finales de la década de 1920, se presenta por primera vez un proyecto de planificación y división de la ciudad en zonas con la Ordenanza de Límites Urbanos en 1928, y los planos de uso del suelo en 1929 (Alcívar, Lee, Luque, Rojas, Valdivieso, 1980, pp. 358 y ss.). Esta ordenanza, que divide el área urbana en cinco sectores, nunca se llevó a cabo y significó el primero de todos los intentos fallidos de planificación urbana que ha tenido la ciudad. ${ }^{6}$

En contraposición con la estructura suburbana del Barrio de El Centenario, las manzanas del centro de Guayaquil de este periodo representan un modelo densamente construido y funcionalmente diversificado. La compleja estructura parcelaria de la manzana aglutina diversidad de usos, construcciones mixtas de hormigón y madera, patios interiores, tragaluces y soportales

\footnotetext{
${ }^{6}$ Para más información sobre el fracaso de la planificación en la ciudad de Guayaquil véase: Peralta, E.; Moya, R. (1979). Guayaquil, planes urbanos (síntesis). Revista Trama, No13-14, Quito: Editorial FRAGA, pp. 10-55.
} 
perimetrales. La estructura parcelaria de la manzana cuadrada es irregular y algunos lotes tienden a ocupar el centro de la manzana y generar pasajes que permiten el acceso a viviendas situadas en áreas internas (Figuras 3 y 4).

A principios de la década de 1930, se inicia el proceso de tugurización de las manzanas del centro y la segregación residencial mediante instrumentos legales con los cuales no se planifica el crecimiento lógico y equitativo de la ciudad, sino que se fomenta un proceso de revalorización de ciertas áreas de la ciudad fomentando además la ocupación ilegal por parte de los inmigrantes de terrenos periféricos municipales (Rojas y Villavicencio, 1988, pp. 78-79). Entre 1900 y 1940, se produce en Guayaquil el cambio de la estructura espacial de un puerto de exportación cacaotera y de importación de productos europeos regido por el liberalismo triunfante de la burguesía, a una metrópolis compleja que debe afrontar los problemas de la ciudad moderna.

Figura 3. Levantamiento arquitectónico de una manzana del centro de Guayaquil
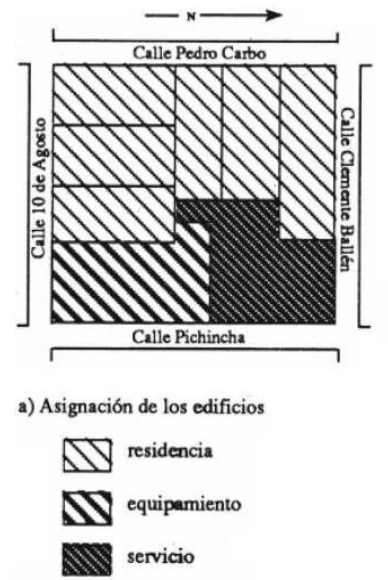

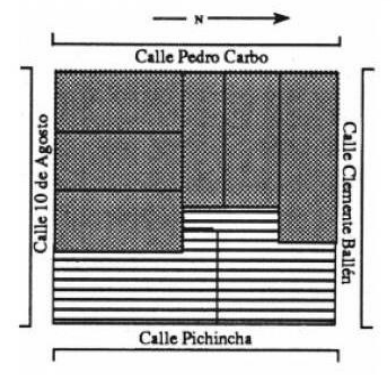

b) Estructura de los edificios

10. madera

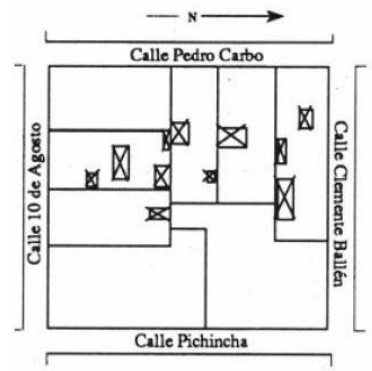

c) Repartición de los tragaluces

$\nabla$

Fuente: Lee; Compte; Palacios, 1987.

Figura 4. Levantamiento arquitectónico de la casa Arturo García en el centro de Guayaquil

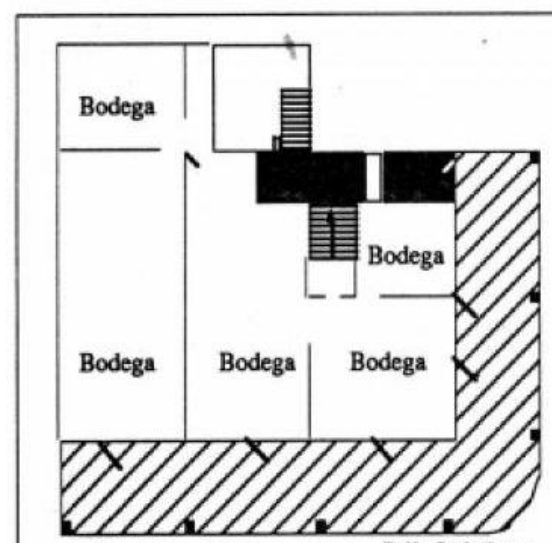

Calle Imbabura
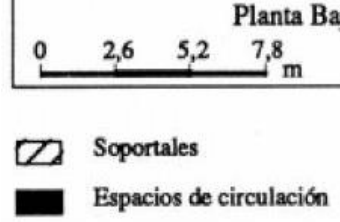

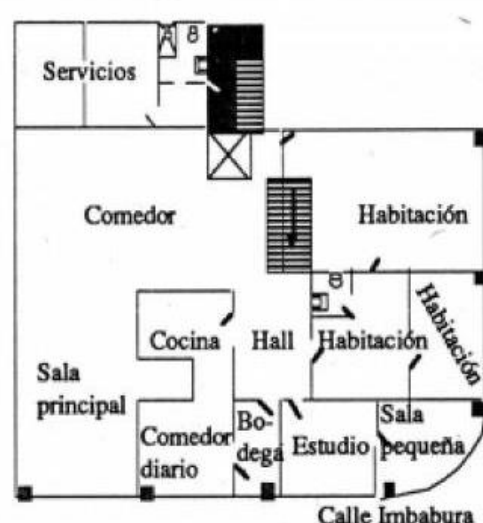

Planta Alta

\section{Planta $A$}

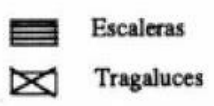

Fuente: Lee; Compte; Palacios, 1987.

ACE, 15 (4.5) CC BY-ND 3.0 ES | UPC Barcelona, España | Caracterización morfo-tipológica de los barrios obreros públicos en la ciudad de Guayaquil (1937-1948). DOI: http://dx.doi.org/10.5821/ace.15.45.9311 


\subsection{La Caja de Pensiones y la Caja del Seguro: las instituciones promotoras de los barrios obreros públicos}

A finales de la década de 1940 se produce un cambio en la especialización productiva del Ecuador hacia los mercados internacionales con la exportación del banano, se inicia lo que se conoce como el "boom bananero" (Rojas y Villavicencio, 1988, p. 71). El nuevo modelo agroexportador de las décadas de 1950 y 1960 trae consigo la estabilidad económica y política lo cual se refleja en el crecimiento poblacional más alto de la historia de la ciudad de Guayaquil y que deviene en un cambio sustancial de su morfología urbana. El periodo de mayor expansión urbana se produce entre 1948 y 1954 y su declive a partir de 1971 (Sánchez, 2015). A diferencia de la economía del cacao, la bananera requiere de más mano de obra rural y urbana, lo cual produjo un importante crecimiento demográfico de la ciudad, que entre 1950 y 1962 creció en un 97,4\%, a una tasa del $7,3 \%$, una de las más altas de Latinoamérica según los datos de las tasas de crecimiento de población de las principales ciudades de la región (Gilbert, 1997).

Este crecimiento urbano acelerado hacia el suroeste y sur de la ciudad se materializa mediante un proceso doblemente destructivo: la ciudad excava los cerros que la rodean para rellenar los esteros ubicados en las zonas de crecimiento. En este proceso de "destrucción creadora", propio de la modernidad, según Harvey $(1990$, p. 26), la ciudad está condenada a destruirse para volver a construirse. En este contexto de procesos acelerados, el "vecindario" latinoamericano comienza a mutar hacia el "barrio" como "recinto primario de lo comunitario" (Almandoz, 2013, p. 193).

Es a partir de la década de 1940, cuando se inician en Guayaquil los proyectos de vivienda promovidos por organismos del Estado para resolver el problema de la vivienda, como son la Caja de Pensiones y la Caja del Seguro (Aguirre, 1984), además de la intervención esporádica de la Municipalidad. Estas realizaciones no se inscriben dentro de una planificación urbana, por lo que sería incorrecto hablar de "programas de viviendas" en el estricto uso del término; son más bien obras realizadas según diversos factores coyunturales como la tenencia de terrenos públicos, la solvencia de los potenciales usuarios, motivos políticos demagógicos e intereses especulativos y financieros de los grandes propietarios urbanos. (Figura 5)

La financiación pública de viviendas aparece vinculada a las instituciones de seguridad social, cuyo primer antecedente es la Caja de Pensiones surgida en 1928, creada dentro de la llamada Revolución Juliana que se dio en 1925 en el periodo de gobierno de Isidro Ayora. El conjunto de reformas modernizadoras que emprendieron se orientaron al fortalecimiento y reorganización técnica del Estado, y han sido consideradas continuadoras del ideario liberal radical de finales del siglo XIX (Paz y Miño Cepeda, 2013). La Revolución Juliana también desarrolla una visión higienista de la sociedad que contempla la erradicación de las enfermedades endémicas, la incorporación a la educación de la idea de higiene, vinculada al aseo del cuerpo, la gimnasia y a la educación sexual y la necesidad de una vivienda con condiciones de salubridad (Sinardet, 1999). Estas prácticas de higiene eran fundamentales en una ciudad como Guayaquil, que se imponía como meta la erradicación de enfermedades como la fiebre amarilla y la peste bubónica, consideradas endémicas y trágicas en su historia por los efectos que ocasionaron.

En 1937, con la Ley de Seguro Social Obligatorio, entra a funcionar la Caja del Seguro para empleados privados y obreros la cual, por primera vez en el Ecuador, financia la adquisición de viviendas a través de préstamos hipotecarios. Las Cajas de Previsión ${ }^{7}$-Caja de Pensiones y Caja del Seguro- se convierten entre las décadas de 1930 y 1960 en agentes influyentes de la política urbana del Estado y por lo tanto en el desarrollo de las áreas urbanas de Quito y Guayaquil (Milton, 2019).

\footnotetext{
7 En 1963 se fusionan la Caja de Pensiones y la Caja del Seguro y se crea la Caja Nacional del Seguro, que posteriormente en 1970 se convierte en el Instituto Ecuatoriano de Seguridad Social (IESS) que funciona en la actualidad.
}

ACE, 15 (4.5) CC BY-ND 3.0 ES | UPC Barcelona, España | Caracterización morfo-tipológica de los barrios obreros públicos en la ciudad de Guayaquil (1937-1948). DOI: http://dx.doi.org/10.5821/ace.15.45.9311 
Figura 5. Ubicación de los casos de estudio en el plano general de Guayaquil de 1952

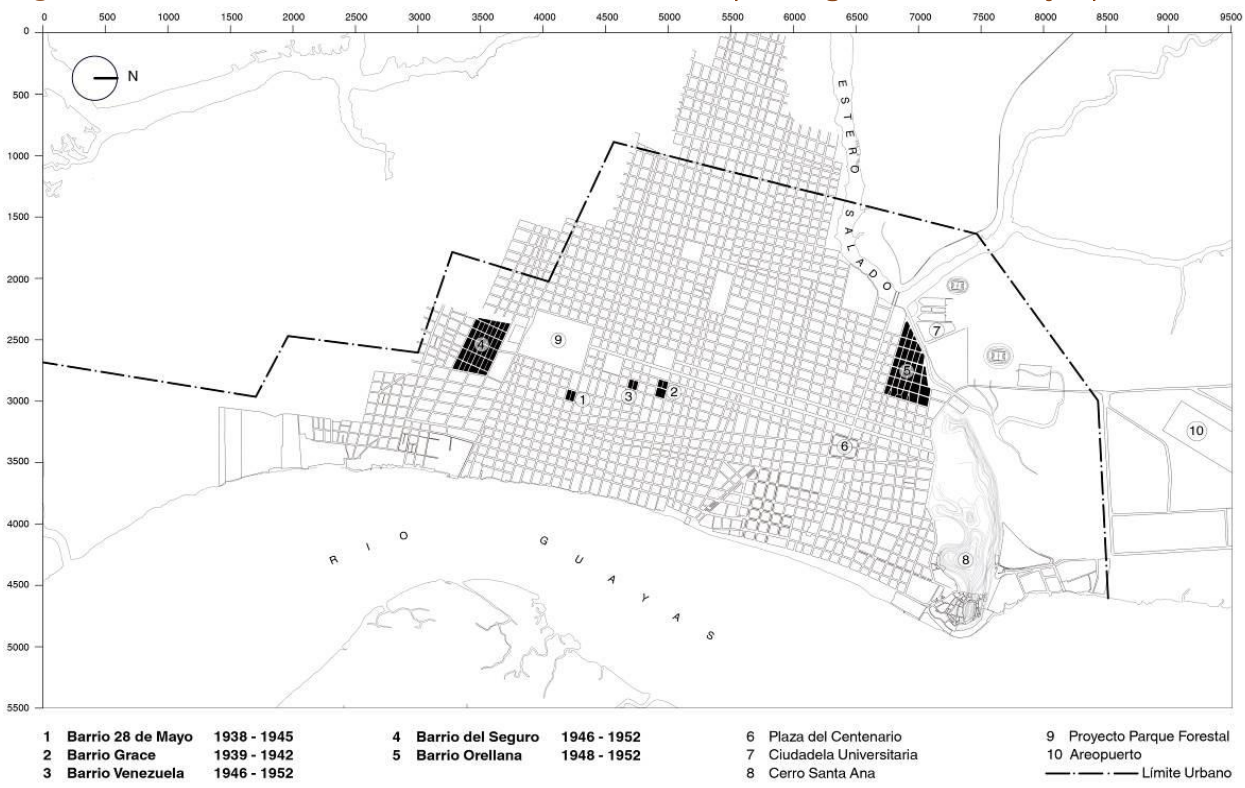

Fuente: extraído de Alcívar, M.; Lee, P.; Luque, S.; Rojas, M.; Valdivieso, F., 1980. Elaborado por el equipo de investigación, 2020.

Figura 6. Delineación del sector Sur Oeste de la Parroquia Ximena donde se ubican el Pasaje 28 de Mayo, el Barrio Grace y el Barrio Venezuela

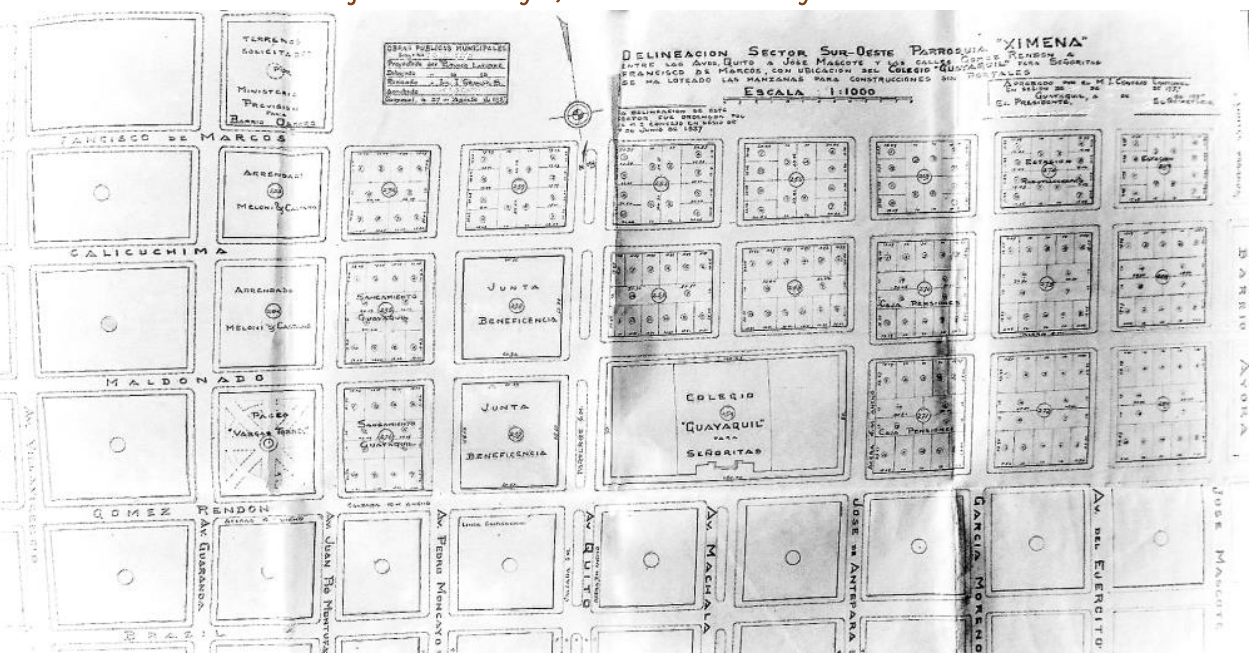

Fuente: Libro de Actas de la Municipalidad de Guayaquil, sesión ordinaria del 26 de octubre de 1937, p. 430. (Archivo Camilo Destruge, Guayaquil).

Los barrios obreros públicos construidos en la década de 1940 (Figura 6), bajo las premisas de economía, durabilidad e higiene, se ubican en zonas periféricas, dentro de los límites urbanos, en terrenos de bajo costo; ejemplo de ello son el Pasaje 28 de Mayo ${ }^{8}$ con 30 unidades adosadas de dos plantas (1938-1945), el Barrio de Empleados con 30 unidades de una planta con retiros laterales, antejardín y jardín posterior (1939-1942), denominado también Barrio Grace por acoger

\footnotetext{
${ }^{8}$ Se denomina "Pasaje 28 de Mayo" en homenaje a la revolución de 1944 que pone en el poder a Velasco Ibarra.
}

ACE, 15 (4.5) CC BY-ND 3.0 ES | UPC Barcelona, España | Caracterización morfo-tipológica de los barrios obreros públicos en la ciudad de Guayaquil (1937-1948). DOI: $\underline{\text { http://dx.doi.org/10.5821/ace.15.45.9311 }}$ 
empleados de la compañía naviera norteamericana Grace Line Ltd. (Compte, 2020, p. 211), y el Barrio Venezuela con 40 unidades (1946-1952) (Lee y Compte, 1992). Los denominados "barrios", en realidad, tenían dimensiones reducidas - no sobrepasan los $8.000 \mathrm{~m}^{2}$-, no cuentan con equipamientos comunitarios y están constituidos por una o dos manzanas (Figura 7a). La acción habitacional de la Caja de Pensiones en Guayaquil financia la adquisición de viviendas producidas por el Departamento de Ingeniería de la propia Caja.

Figura 7a. Fotografías de izquierda a derecha Pasaje 28 de Mayo, Barrio Grace y Barrio Venezuela

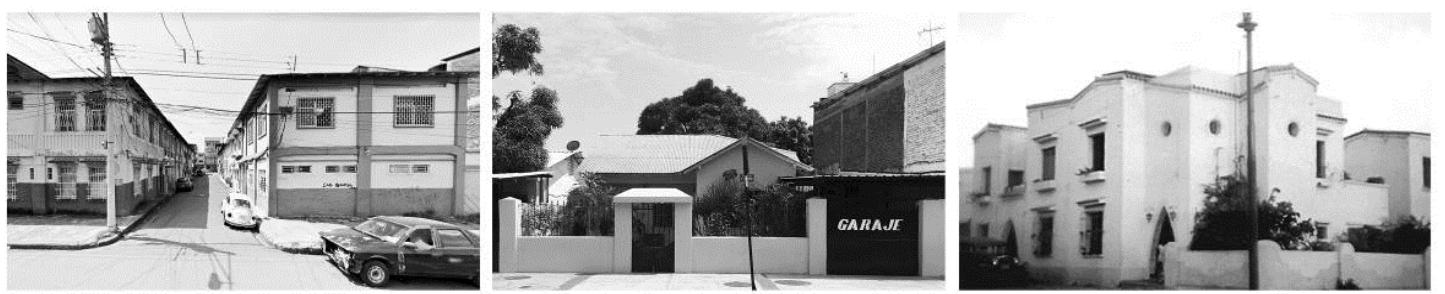

Fuente: Recuperado de https://www.facebook.com/Guayaquil2020/photos/?ref=page internal.

Estos barrios constituyen claros ejemplos del modelo de "ciudad-jardín”. El modelo importado es la company town, pensado como una pequeña ciudad dependiente de una compañía. Se configuran como asentamientos horizontales en hileras de casas unifamiliares -inspiradas en el modelo de vivienda obrera cottage $-{ }^{9}$ de uno o dos pisos cuya organización territorial está estrechamente ligada a las necesidades de la industria (Martín Hernández, 2014, p. 52). A partir de las experiencias de las company town europeas, y en alguna medida las norteamericanas, se desarrollarán las ideas de la ciudad-jardín promulgadas por Ebenezer Howard (Panerai, 1986). La ciudad-jardín constituye la visión idílica de las company town cuyo criterio básico es la autosuficiencia económica con respecto al tejido urbano y la negación de la ciudad. Los primeros barrios obreros en Guayaquil, al estar insertados en la retícula urbana en sectores relativamente céntricos y estar constituidos por pocas manzanas, no mantienen el ideal "antiurbano" que promulga la ciudad-jardín —en cuanto que va en contra de la ciudad-, pero asume las formas de agrupación y los tipos edificatorios que la caracterizan.

La vivienda obrera debe ser higiénica y saludable por lo que se ubican patios abiertos tanto en la parte delantera como en la trasera de la casa. El jardín delantero desaprovecha el confort climático que garantiza el soportal como un espacio característico de la arquitectura tradicional de la ciudad que resuelve la transición entre lo público y lo privado con una intensa función económica y social vinculada al comercio del cacao. Este espacio intermedio si mantiene, por otro lado, la ambigüedad de uso y la relación con la calle que favorece la vida cotidiana a escala de barrio.

En el interior de algunas manzanas, surgen unos callejones peatonales que dividen la parcelación en dos pseudo manzanas menores, que recuperan la tradición de los pasajes que atraviesan irregularmente las manzanas del centro histórico siguiendo el cauce de los esteros (Estrada Ycaza, 2000, pp. 64-65). El pasaje de las manzanas de los barrios obreros, al igual que el soportal en el perímetro de la manzana, incorpora una nueva escala de espacio de relación entre la vivienda y la calle en la que desaparece el patio interior del "tugurio" en favor de una calle peatonal con jardines privados semiabiertos.

Desde finales de la década de 1940 y durante la de 1950, se construyen barrios de mayores dimensiones como el Barrio del Seguro con un total de 641 viviendas de diferentes tipos (1946-1952)

\footnotetext{
${ }^{9}$ Ejemplares son los modelos de vivienda obrera -denominados Prince Albert model cottages- diseñados por Henry Roberts en la Gran Exposición de Londres de 1851.
}

ACE, 15 (4.5) CC BY-ND 3.0 ES | UPC Barcelona, España | Caracterización morfo-tipológica de los barrios obreros públicos en la ciudad de Guayaquil (1937-1948). DOI: http://dx.doi.org/10.5821/ace.15.45.9311 


\section{ACE Architecture, City and Environment}

(Figura 7b) y el Barrio Orellana (1948-1952). Se inicia la participación múltiple entre el Municipio, que urbaniza los terrenos y los dota de infraestructura, y la Caja del Seguro, que construye algunas casas y vende terrenos urbanizados a empresas con el fin de construir viviendas para los empleados de las industrias. De esta forma se genera diversidad de habitantes de diferentes sectores socioeconómicos y variedad tipológica ya que cada institución adopta modelos arquitectónicos diferentes.

Figura 7b. Recortes de periódico y fotografías sobre la construcción del Barrio del Seguro

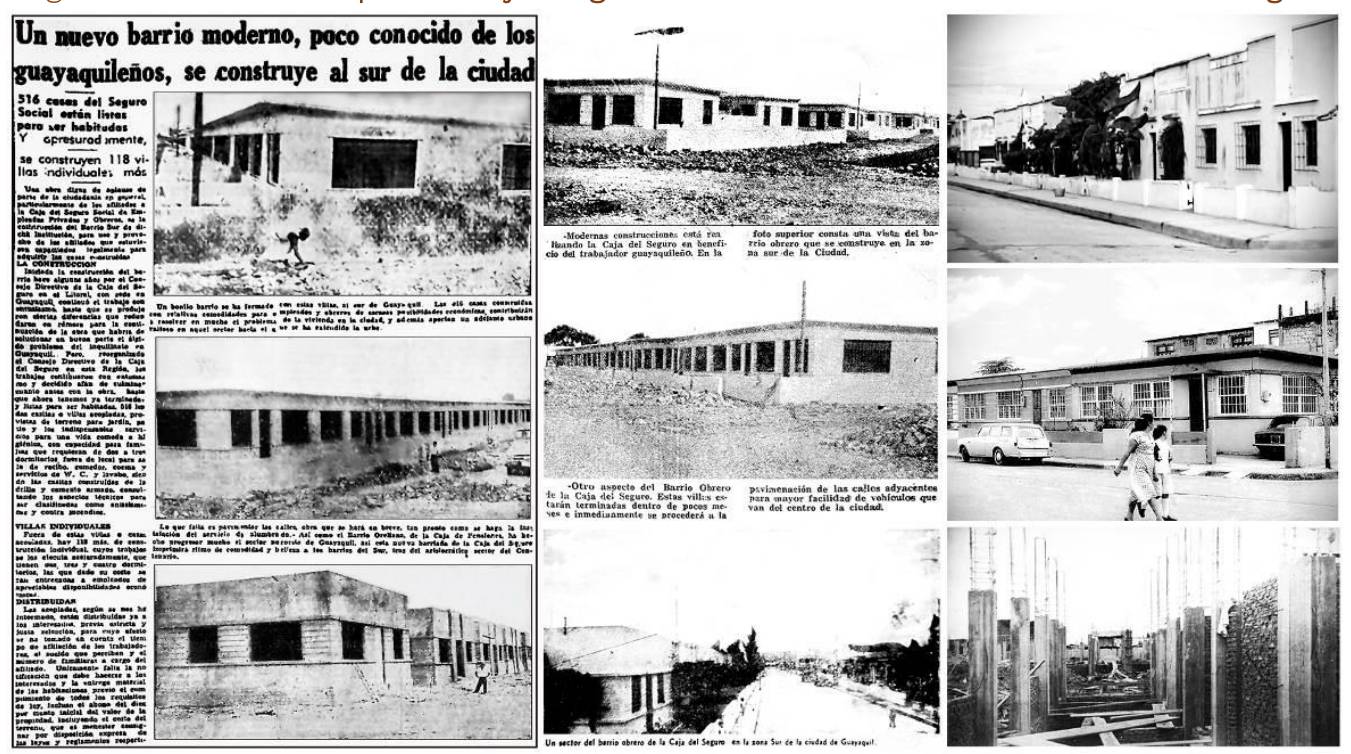

Fuente: Diario La Nación, 1951 y Archivo personal Antonio Ubilla.

Estos barrios, a diferencia de los del periodo anterior, sí inciden en el crecimiento de la ciudad, especialmente hacia el norte con el Barrio Orellana, al haber sido dotados esos sectores de infraestructura básica por parte del Municipio (Alcívar, Lee, Luque, Rojas, Valdivieso, 1980, pp. 471504). Se caracterizan por el aumento considerable de las dimensiones y por la incorporación de servicios comunitarios que los convierten en barrios autosuficientes que generan ciertos cambios estructurales en el tejido urbano y el crecimiento de la urbe (Figura 7c).

Figura 7c. Recortes de periódico y fotografías del Barrio Orellana
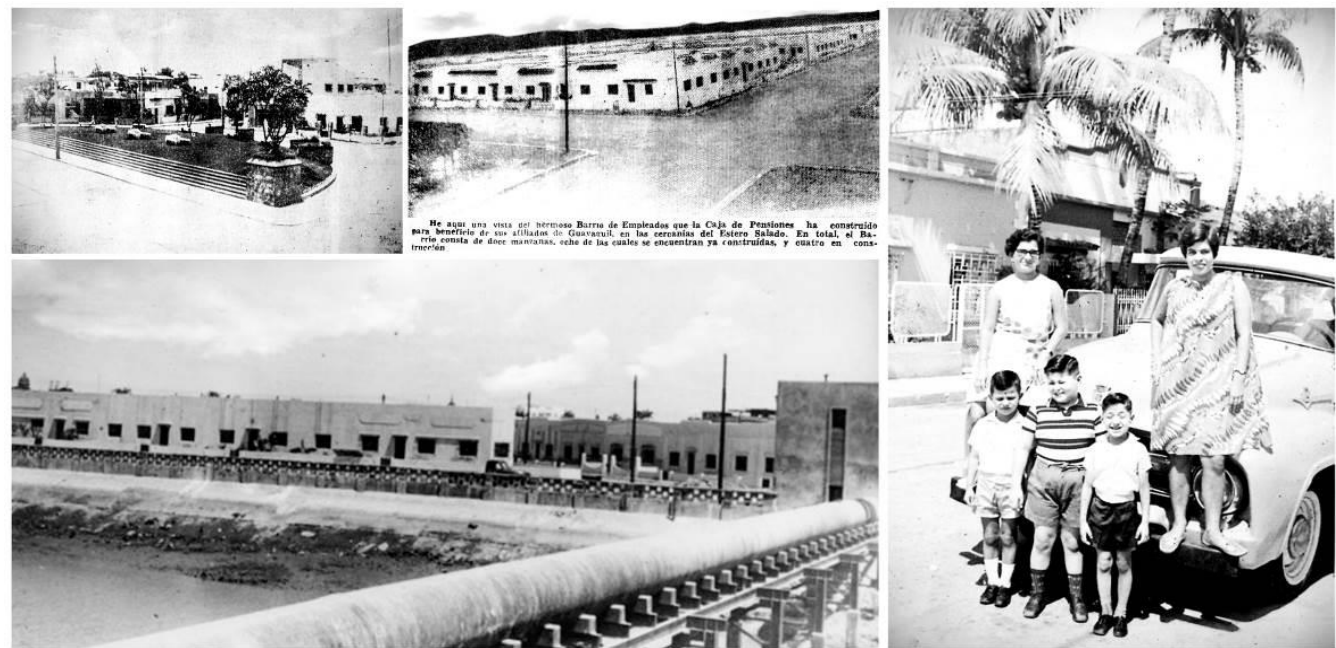

Fuente: Archivos personales de John Orellana y Antonio Ubilla.

ACE, 15 (4.5) CC BY-ND 3.0 ES | UPC Barcelona, España | Caracterización morfo-tipológica de los barrios obreros públicos en la ciudad de Guayaquil (1937-1948). DOI: http://dx.doi.org/10.5821/ace.15.45.9311 
La Ciudadela 9 de octubre (1957) y la Ciudadela Bolivariana (1957-1962), abren una nueva etapa en la concepción de los conjuntos de vivienda pública, ya que abandonan las tendencias del racionalismo arquitectónico incipiente de los primeros barrios obreros, para decantarse cada vez más por modelos norteamericanos influyentes en el imaginario de las clases medias guayaquileñas favorecidas con los excedentes de la producción bananera. Estas formas de vida al "estilo americano" significan un aumento drástico de la segregación social y la fragmentación del tejido urbano que la propia etimología del término "ciudadela" promueve. Estas urbanizaciones las habitan grupos sociales homogéneos que pertenecen a las mismas organizaciones; aunque no existe una delimitación física en forma de muralla, los conjuntos generan una distinción morfológica evidente con respecto al tejido existente que marca el cambio de modelo del "barrio abierto" a la "ciudadela cerrada”. Este cambio morfo-tipológico es el que marca el final del periodo de estudio de la presente investigación.

\section{Caracterización morfo-tipológica de los casos de estudio}

En una primera observación de los casos de estudio, se identifica una notoria heterogeneidad de las formas urbanas y los tipos edificatorios que difícilmente se podrían clasificar en un modelo, estilo, lenguaje o corriente teórico-práctica común. Incluso internamente cada caso presenta un cierto eclecticismo, una posición intermedia que no se opone a ninguna de las corrientes, capaz de mezclar formas y lenguajes al margen de la ortodoxia moderna. Tampoco se observa una evolución lógica de las formas y tipos sino más bien respuestas que tienen que ver con la experimentación, la improvisación y el pragmatismo ante diferentes condiciones. Como hemos visto en los antecedentes históricos las premisas fundamentales con las que se rigen todos los proyectos son la economía, la durabilidad y la higiene propias de los principios de la arquitectura de vivienda moderna.

Una de las cuestiones principales, que afecta de manera crucial a la morfología urbana y, sobre todo, a los tipos edificatorios, es la eliminación del soportal como elemento obligatorio según las ordenanzas municipales (ACG 29 de octubre de 1937). Como consecuencia directa de esta decisión normativa se abandona este recurso funcional de primer orden y se sustituye por un campo de soluciones más o menos acertadas sobre la articulación entre lo público y lo privado que abarcan desde el patio frontal semi-abierto a la galería o porche de entrada a la casa. Se trata de un sistema de espacios discontinuos — lejos de la continuidad del conjunto de soportales - que tiende a ser más una extensión del espacio doméstico que una ampliación de lo público como sucedía con el soportal.

Una condición común a todos los casos, en lo que respecta a la forma urbana, es la liberación de suelo de uso público producida por el pasaje interior a las manzanas como elemento vertebrador de la vida en comunidad cuyo principal exponente es el Pasaje 28 de Mayo. Otra condición sería la incipiente racionalización de las estructuras - que nunca estuvo acompañada de una innovación en los sistemas constructivos - y la estandarización de tipos de viviendas higiénicas y confortables agrupadas a través de un sistema viario claro y eficiente. Por otro lado, en la mayoría de proyectos se observa una falta de reflexión sobre la resolución de las edificaciones esquineras y los lados cortos de las manzanas rectangulares alargadas, especialmente notable en el caso del Barrio Orellana. A continuación, se plantea un análisis de los resultados obtenidos mediante el levantamiento arquitectónico sistemático ordenando los casos de estudio según el año de los diseños originales - que es el punto que marca la concepción de los diferentes modelos y tipos- y no respecto al año de terminación de la obra: el Pasaje 28 de Mayo (1938-1945), el Barrio Grace (1939-1942), el Barrio Venezuela (1946-1952), el Barrio del Seguro (1946-1952) y el Barrio Orellana (1948-1952) (Figura 8).

ACE, 15 (4.5) CC BY-ND 3.0 ES | UPC Barcelona, España | Caracterización morfo-tipológica de los barrios obreros públicos en la ciudad de Guayaquil (1937-1948). DOI: http://dx.doi.org/10.5821/ace.15.45.9311 
Figura 8. Matriz gráfica de los cinco casos de estudios en las tres escalas de análisis

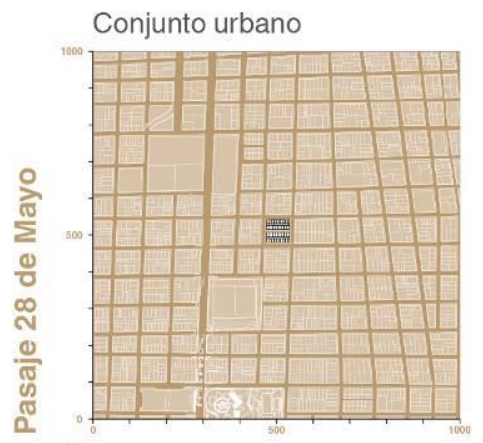

Agrupación de viviendas
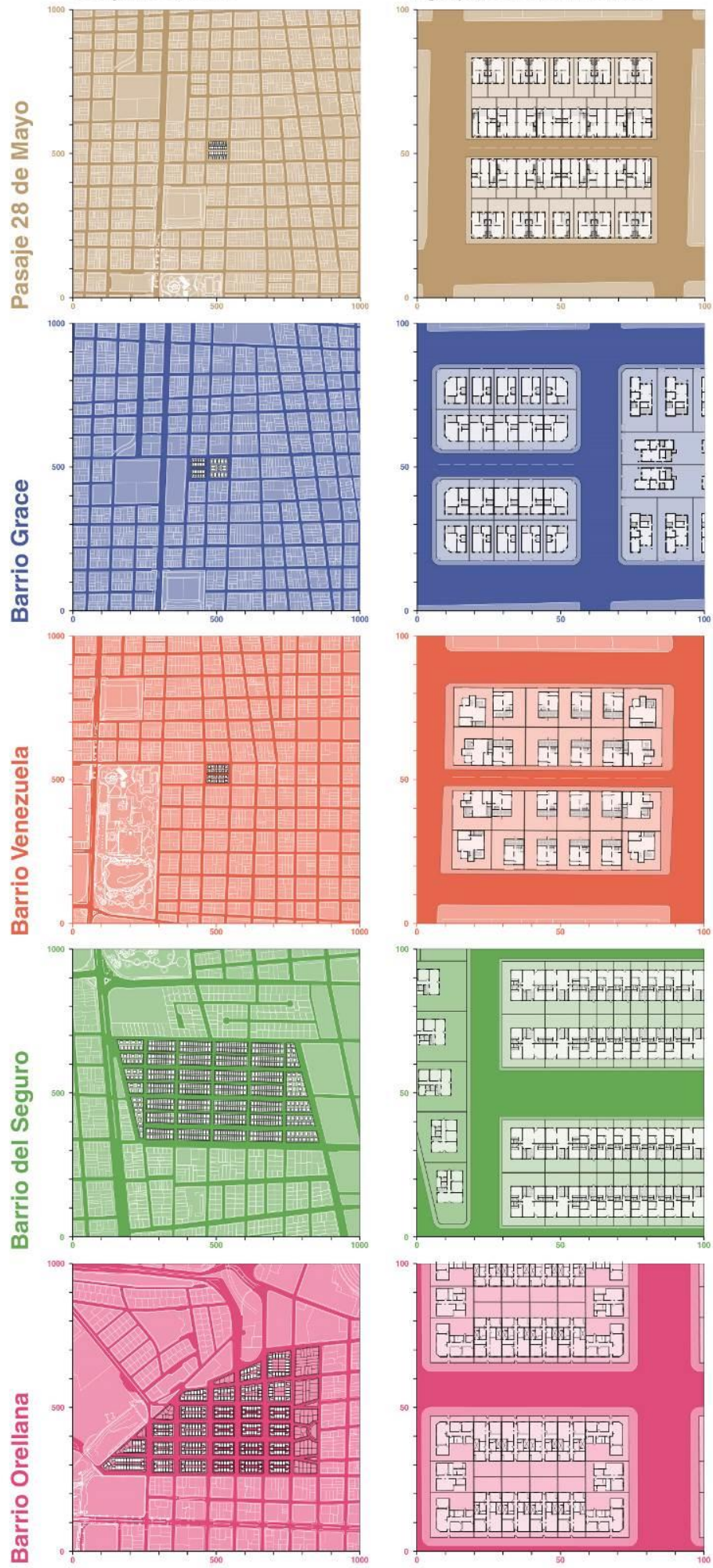
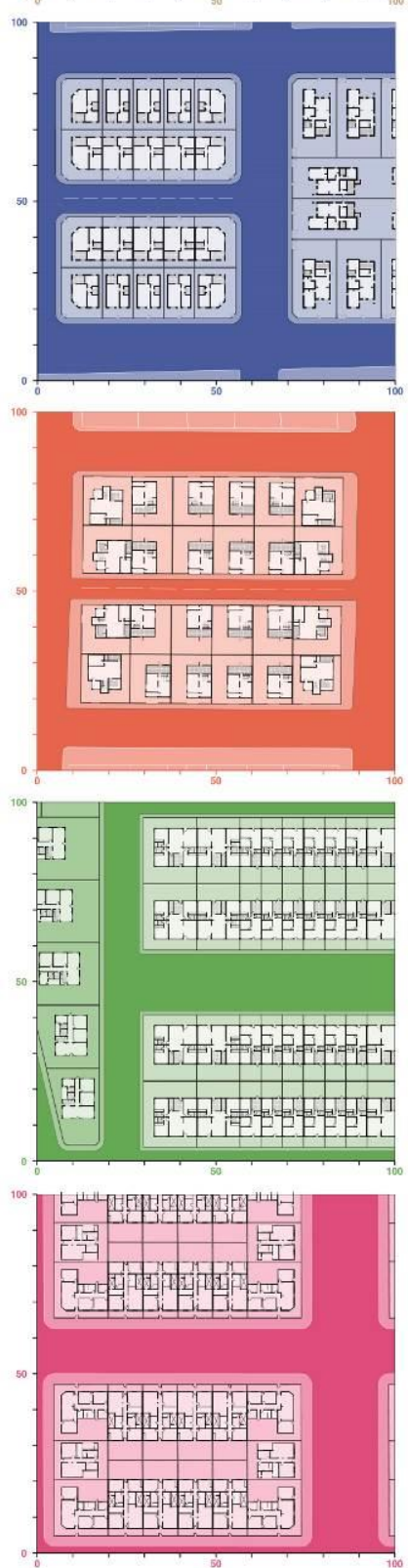

Tipología de viviendas
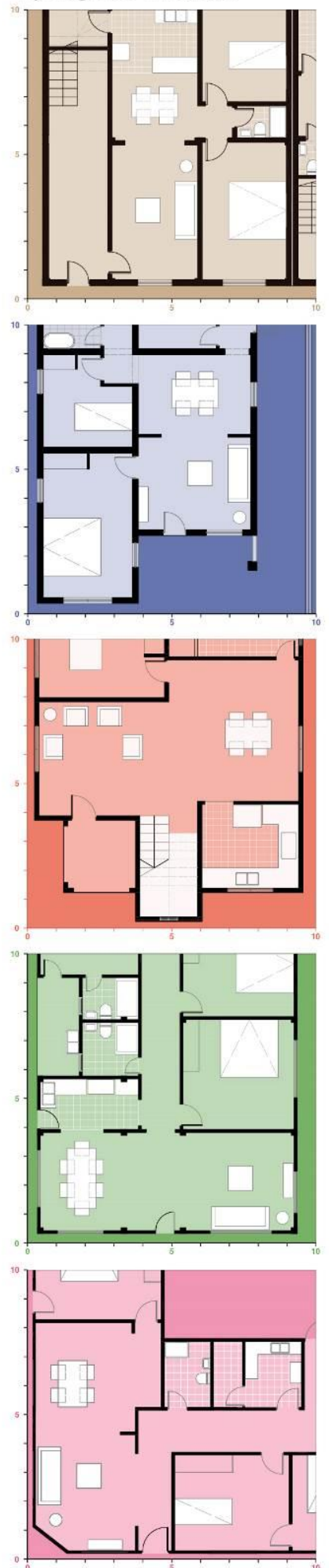

Fuente: Elaborado por el equipo de investigación, 2020. 


\subsection{El Pasaje 28 de Mayo: la manzana de alta densidad con pasaje}

El Pasaje 28 de Mayo, diseñado hacia 1938, constituye la primera concepción de manzana de alta densidad de viviendas mediante la incorporación del pasaje interior como elemento estructurador del conjunto urbano. El pasaje de manzana es un recurso utilizado en los tugurios de casas populares del centro histórico de la ciudad de Guayaquil - en ocasiones vinculados al curso de los esteros como el caso del callejón Magallanes- para resolver el acceso a las viviendas de las zonas centrales de la manzana: el problema de los grandes fondos de parcela de la manzana cuadrada, de ochenta varas en cuadro, típica de la retícula colonial (Panerai, 2002).

El pasaje divide la única manzana que conforma el barrio - en el proyecto original se contemplaban dos pero finalmente se construyó solo una-, en dos manzanas alargadas menores conformadas por lotes que dan hacia las calles principales y hacia el propio pasaje. Se trata de una calle con vocación peatonal por la que se ingresa a una hilera de viviendas adosadas en las que se alternan tipos unifamiliares de dos niveles con escalera interna y viviendas bifamiliares con un espacio reducido de circulación externa. El ritmo de las fachadas, que alterna dos crujías de mayor tamaño con una menor, no muestra las diferencias tipológicas interiores; la homogeneidad de la imagen urbana del pasaje prevalece sobre los pormenores de una vida doméstica compleja y diversificada (Figura 9a).

Figura 9a. Elevaciones y secciones del Pasaje 28 de Mayo

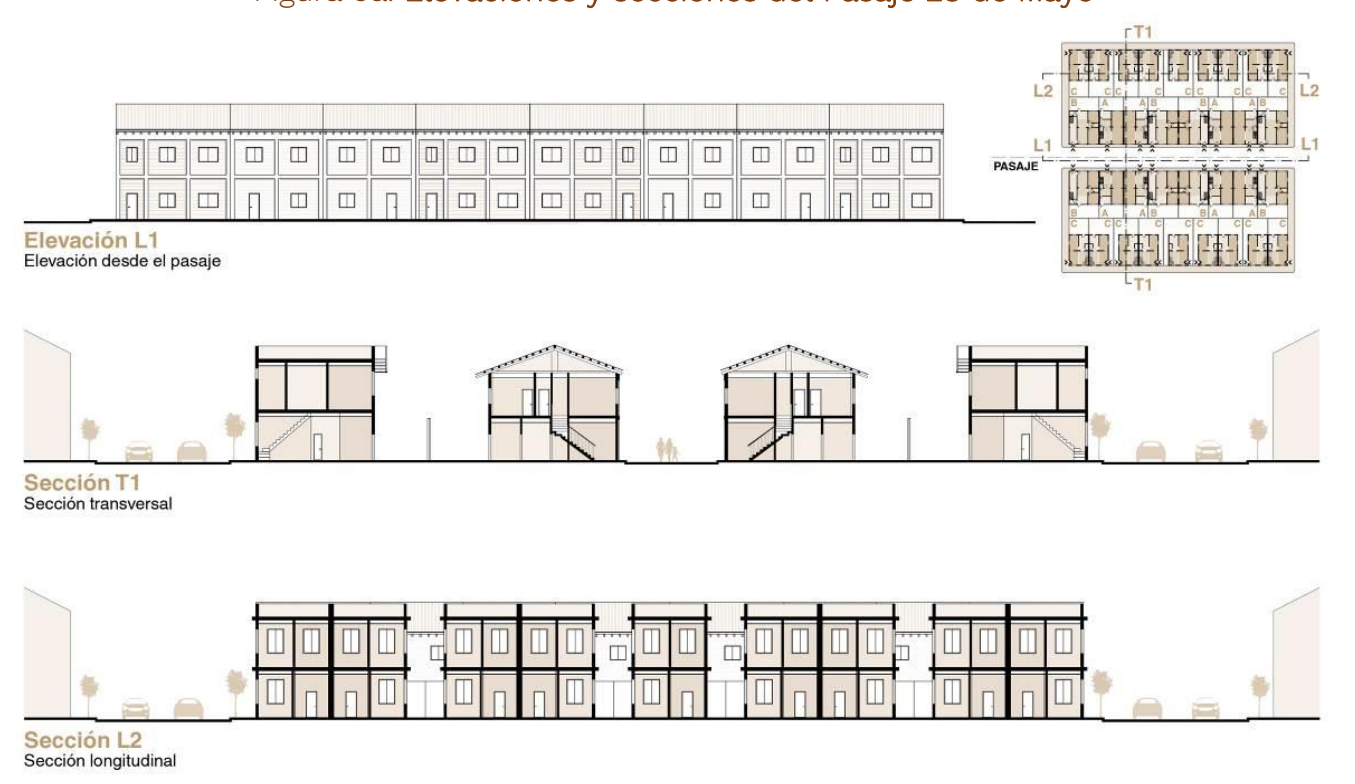

Fuente: Elaborado por el equipo de investigación, 2020.

El conjunto plantea una notable diversidad de tipos de viviendas sin la necesidad de generar grandes variaciones volumétricas incluso acudiendo a una doble simetría simplificadora. Los tipos que se vuelcan hacia el pasaje interior están adosados y presentan un ritmo de las crujías estructurales que va alternando dos módulos de mayor tamaño con uno menor en el que se ubican los núcleos de circulación vertical. Este ritmo permite introducir viviendas unifamiliares de dos niveles y escaleras interiores (tipología A01), con viviendas bifamiliares que se articulan a través del espacio de servicio donde se ubica el núcleo de escaleras (tipología B01). Esta lógica produce una condición de homogeneidad hacia el pasaje que esconde un intrincado y diverso mundo residencial interior. Todas las viviendas tienen un patio trasero y se rematan con una cubierta inclinada que se experimenta desde el interior de las viviendas de planta alta y no desde el exterior.

ACE, 15 (4.5) CC BY-ND 3.0 ES | UPC Barcelona, España | Caracterización morfo-tipológica de los barrios obreros públicos en la ciudad de Guayaquil (1937-1948). DOI: http://dx.doi.org/10.5821/ace.15.45.9311 
Las viviendas que dan hacia las calles principales son villas unifamiliares pareadas de mayor tamaño que presentan retiros laterales por los que se produce el acceso (tipología C01). Estas edificaciones están adosadas en una de las caras y tienen un retiro lateral y un patio trasero al que se accede por dicho retiro. Estas viviendas están compuestas de dos niveles y escaleras internas. La distribución es semejante a las unifamiliares del pasaje, pero con medidas más reducidas y con aperturas de ventanas en la fachada del retiro lateral. La alta densidad del proyecto tiene como precio la eliminación de los retiros frontales que tanto se repetirán en los siguientes casos de estudio.

Las esquinas de la manzana se resuelven con variaciones en la estructura y formas de acceso a la vivienda diferentes que resaltan funcionalmente la importancia del encuentro entre calles sin necesidad de recurrir a formalismos. Las viviendas esquineras presentan la particularidad de incorporar desde el proyecto una escalera que sube a un tercer nivel donde se desarrolla una cubierta plana y un posible crecimiento de la vivienda. La racionalidad de la estructura se expresa en las pilastras de las fachadas y resuelve la composición del conjunto con austeridad y sencillez (Figura 9b).

Figura 9b. Diagrama de las tipologías de viviendas del Pasaje 28 de Mayo

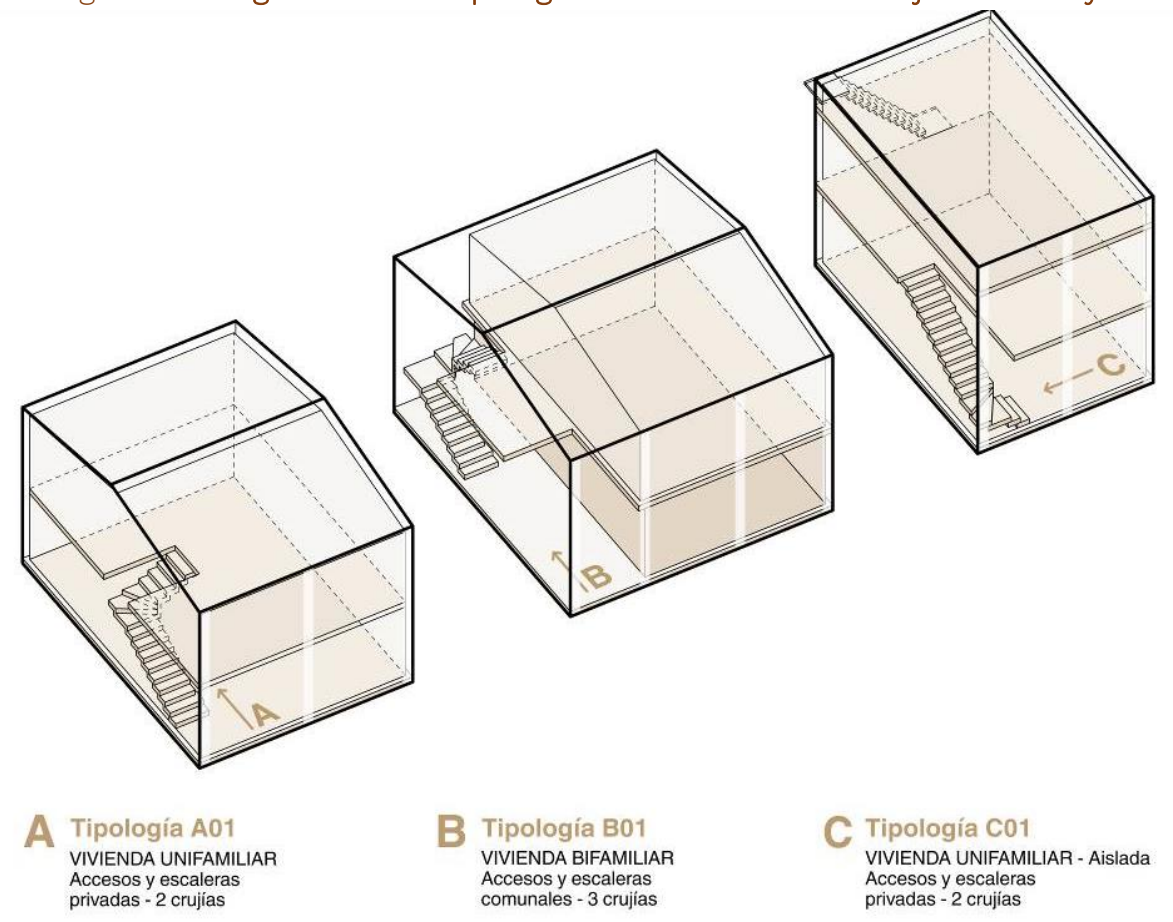

Fuente: Elaborado por el equipo de investigación, 2020.

\subsection{El Barrio Grace: un nuevo modelo de configuración de la manzana cuadrada}

El Barrio Grace, es un ejemplo modélico de resolución de la configuración de la manzana cuadrada mediante dos organizaciones urbanas alternativas. El barrio, que fue diseñado y construido por el arquitecto italiano Francesco Maccaferri (Compte, 2020), se compone de dos manzanas: una manzana se resuelve acudiendo de nuevo al pasaje como elemento vertebrador (agrupación tipo 1A) y la otra se configura mediante la división en tres partes que posibilita el acceso a distintas viviendas por los cuatro lados de la manzana (agrupación tipo 2A). Las dos manzanas constituyen un laboratorio de formas de estructuración de una manzana cuadrada (Figura 10a). 


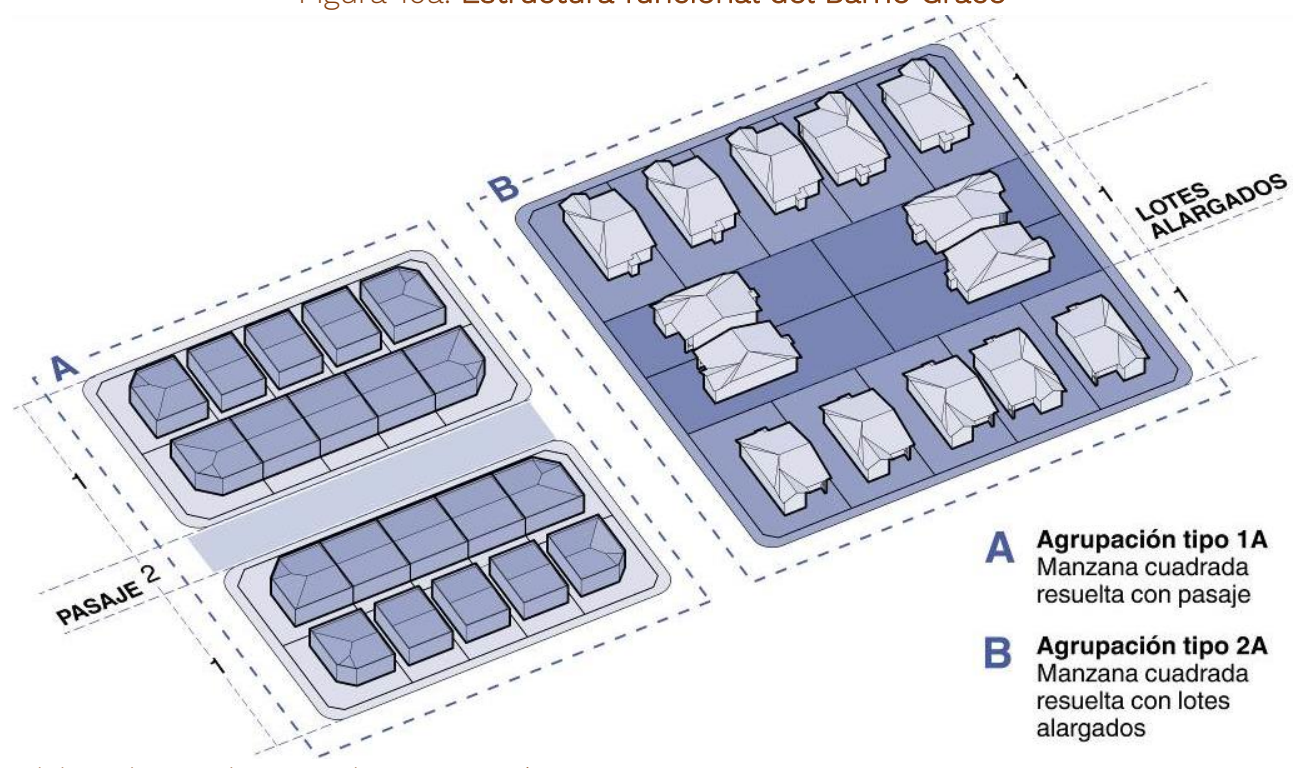

Fuente: Elaborado por el equipo de investigación, 2020.

La manzana del pasaje (1A), repite la configuración del Pasaje 28 de mayo con las viviendas unifamiliares adosadas orientadas hacia el interior del pasaje y viviendas unifamiliares de un nivel con pequeños retiros laterales dando hacia las calles principales (Gómez Rendón y Pedro Vicente Maldonado). La manzana 2A, que se divide en tres partes iguales, se compone de villas aisladas de una planta de mayores dimensiones con amplios jardines delanteros y traseros. En las estructuraciones parcelarias de las manzanas del centro histórico (véase Figura 3), se observa el problema geométrico y ambiental de las viviendas que se construyen en los lotes que dan a las calles secundarias. La configuración parcelaria de esta manzana resuelve equitativamente las dimensiones de los espacios libres y la implantación de las viviendas de los cuatro lados.

Figura 10b. Elevaciones y secciones del Barrio Grace

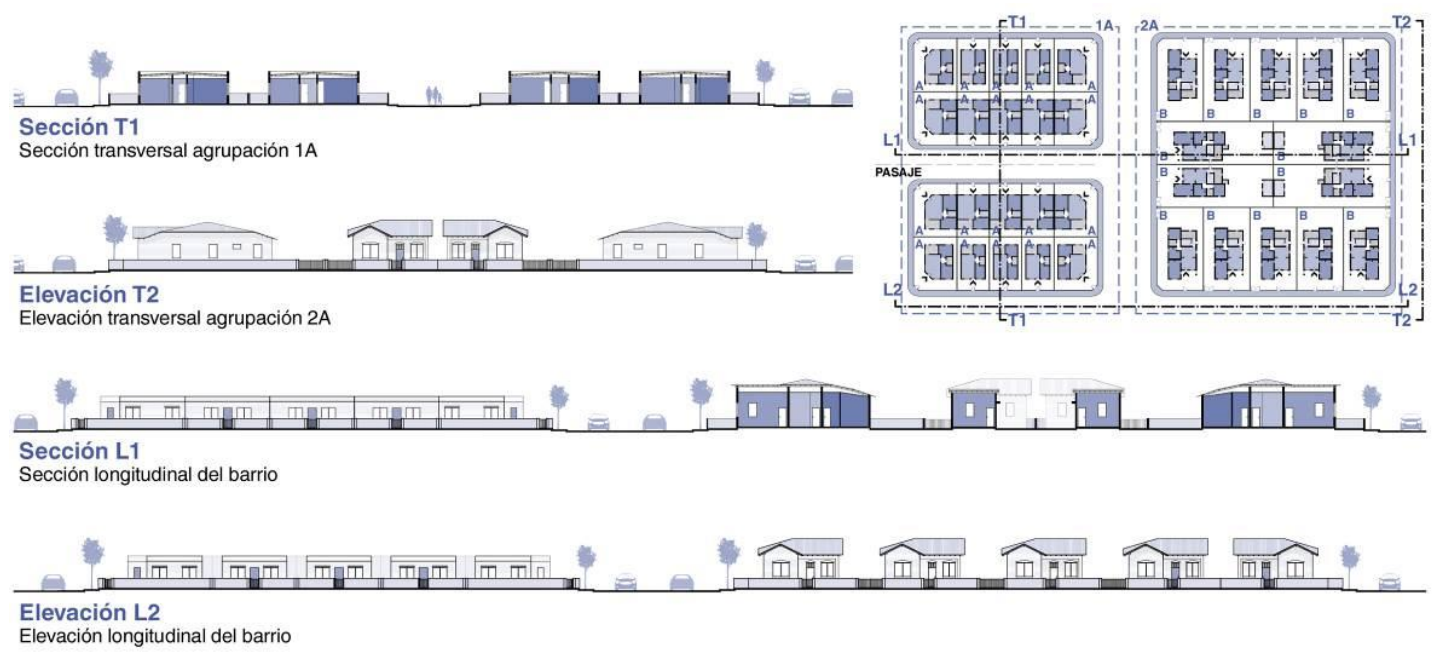

Fuente: Elaborado por el equipo de investigación, 2020.

Los tipos de viviendas de la manzana 1A, presentan superficies útiles que varían de los 50 a los 70 $\mathrm{m}^{2}$. Las variaciones de los tipos dentro de la manzana radican fundamentalmente en su

ACE, 15 (4.5) CC BY-ND 3.0 ES | UPC Barcelona, España | Caracterización morfo-tipológica de los barrios obreros públicos en la ciudad de Guayaquil (1937-1948). DOI: http://dx.doi.org/10.5821/ace.15.45.9311 
implantación dentro de la parcela, ya que las villas que dan hacia el pasaje son adosadas en sus laterales, mientras que las que dan hacia las calles exteriores poseen retiros laterales mínimos que a diferencia de los del Pasaje 28 de Mayo no sirven como lugar de ingreso a la vivienda ya que el acceso aquí se produce frontalmente y no tangencialmente. Si bien esto influye en la superficie de cada tipo, no impide mantener la misma organización funcional interna en la que al ingresar a la vivienda el área social es el recibidor que distribuye hacia los espacios más privados. En cuanto al lenguaje de las fachadas, las viviendas expresan un total purismo volumétrico, con pocos y reducidos elementos sobresalientes en las puertas y ventanas. Al igual que en el Pasaje 28 de Mayo, el remate ortogonal de la cornisa esconde una cubierta inclinada.

Las viviendas de la agrupación 2A, la cual se caracteriza por la fragmentación regular de la manzana, tienen áreas cercanas a los $90 \mathrm{~m}^{2}$ y se implantan de forma aislada separándose de los cuatro lados para conseguir que todos los espacios internos estén iluminados y ventilados. La organización funcional de estas villas se resuelve a partir de un hall de ingreso que comunica al área social la cual articula los espacios de servicio y los dormitorios; todas las viviendas tienen tres dormitorios y las parcelas intermedias con patios traseros más amplios tiene un cuarto de servicio aislado al final del mismo. El modelo cottage tiene en estas villas de carácter suburbano con notables cubiertas a dos aguas su mayor expresión en la arquitectura de vivienda de Guayaquil (Figura 10b).

\subsection{El Barrio Venezuela: un modelo híbrido entre la villa y el pasaje}

El Barrio Venezuela, situado al este del Parque Forestal sobre la calle Venezuela, se caracteriza por ser un modelo híbrido entre la manzana de villas aisladas con amplios retiros en forma de jardines privados y la manzana densa con pasaje y viviendas adosadas o pareadas. Se trata de una única manzana en la que se experimenta con estos dos modelos de configuración de lotes y tipos de viviendas: las villas dan a las calles principales y las viviendas pareadas hacia el pasaje interior (Figura 11a).

\section{Figura 11a. Elevaciones del Barrio Venezuela}

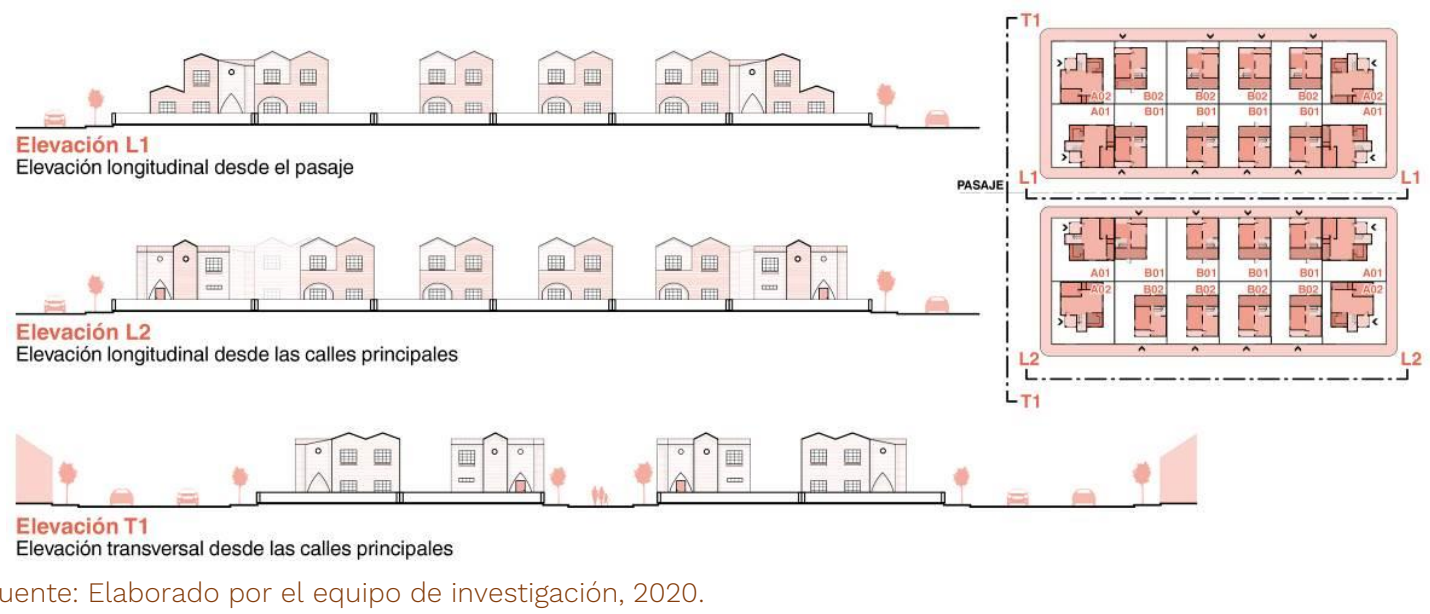

El pasaje del Barrio Venezuela, que, a diferencia del Barrio Grace, recupera las generosas dimensiones del Pasaje 28 de Mayo, se articula con una combinación de jardines, garajes y viviendas unifamiliares pareadas con un pequeño porche de acceso que de forma tímida trata de resolver la transición entre la calle y la casa que resolvía el soportal. En cambio, hacia las calles principales Portete y Venezuela, las viviendas aisladas presentan retiros frontales en forma de

ACE, 15 (4.5) CC BY-ND 3.0 ES | UPC Barcelona, España | Caracterización morfo-tipológica de los barrios obreros públicos en la ciudad de Guayaquil (1937-1948). DOI: http://dx.doi.org/10.5821/ace.15.45.9311 
jardines que resaltan una arquitectura formalista con cubiertas inclinadas y elementos decorativos que denotan el carácter de una villa suburbana.

Los tipos esquineros del Barrio Venezuela se destacan por sus peculiares características formales. Se trata de villas unifamiliares de dos plantas que se configuran con un juego de volúmenes que rompe con la volumetría de la vivienda cajón del pasaje; además presentan una mezcla estilística que incorpora arcos de medio punto y ojivales, cubiertas inclinadas con diferentes caídas y pequeñas cornisas con adornos diversos. La estructura funcional de las villas parte de un hall cubierto que conecta directo al área social y a las escaleras; en planta baja existe un dormitorio cerca del área de servicio, mientras en las plantas altas los tipos alternan entre dos y tres dormitorios. Las viviendas medianeras, aunque de menores dimensiones, mantienen las mismas características estilísticas, y su distribución de igual forma parte de un hall de acceso que conecta el área social y el comedor con las escaleras que llevan a la planta alta compuesta de dos dormitorios y un baño (Figura 11b).

Figura 11b. Diagrama de implantación de las tipologías de vivienda del Barrio Venezuela

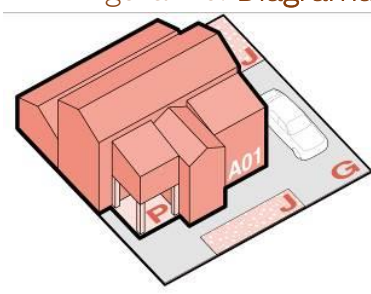

Villa esquinera

A01 Colindante con el pasaje

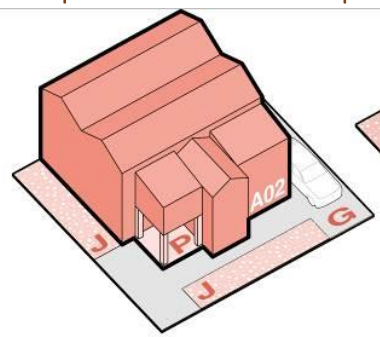

Villa esquinera

A02 Colindante con las vías principales
Villa medianera
Colindante con el pasaje

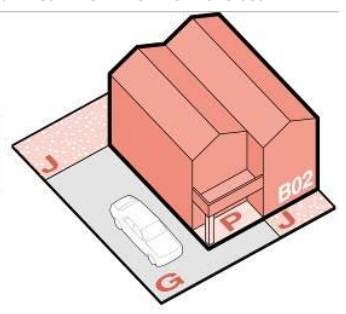

Villa medianera

B02 Colindante con las vías principales

J Jardin G Garaje P Porche

Fuente: Elaborado por el equipo de investigación, 2020.

\subsection{El Barrio del Seguro: el primer gran barrio obrero}

El Barrio del Seguro es también conocido como Barrio Obrero o Ciudadela de las Américas (debido a que todas las calles se designaron con nombres de capitales de los países americanos) y se sitúa próximo al Barrio del Centenario en áreas de ramales del estero Salado rellenadas en la década de 1940 (Rojas, 2019). Este barrio se convierte en el primer gran barrio obrero de la ciudad de Guayaquil por sus dimensiones y por la incorporación de diversos servicios internos que resuelven las necesidades básicas de las familias que le otorgan una cierta autosuficiencia. El barrio lo componen una importante cantidad de manzanas alargadas en la parte central y otras de forma trapezoidal en los extremos configurando los bordes irregulares e integrándose al tejido existente.

Las manzanas rectangulares (agrupación 1A) están conformadas por viviendas unifamiliares adosadas de una planta con un pequeño retiro frontal y otro trasero. En las manzanas trapezoidales (agrupación 3A y 4A) se implantan viviendas unifamiliares aisladas de una planta. La manzana alargada se lleva al extremo en este proyecto generando agrupaciones de hasta 26 viviendas (13 en cada lado) con los accesos dando hacia las calles longitudinales; estas calles van alternando el ancho generándose unas de carácter más peatonal y otras con una condición más vehicular de conexión con el tejido de los barrios inmediatos (Figura 12a).

El proyecto plantea dos tipos de viviendas: unas adosadas y otras aisladas, que a su vez definen dos tipos de agrupación en manzanas regulares e irregulares respectivamente. El tipo de vivienda 


\section{ACE Architecture, City and Environment}

más característico y que más se repite en la estructura del barrio es la vivienda adosada con retiro frontal y trasero. Se implantan dos variantes del tipo adosado: en las esquinas se adosan dos viviendas que presentan tres crujías estructurales y en el centro se desarrollan viviendas de dos crujías. Las viviendas de mayor tamaño se organizan ubicando el espacio social en el centro y tres habitaciones con tres baños y la cocina en torno a ese espacio central. Los tipos más reducidos agrupan las habitaciones y un baño en una crujía y la sala, el comedor y la cocina con un pequeño aseo en la otra crujía; ambas viviendas presentan un jardín delantero a modo de umbral entre la calle y la casa y un patio trasero privado.

Figura 12a. Diagrama de la implantación del Barrio del Seguro

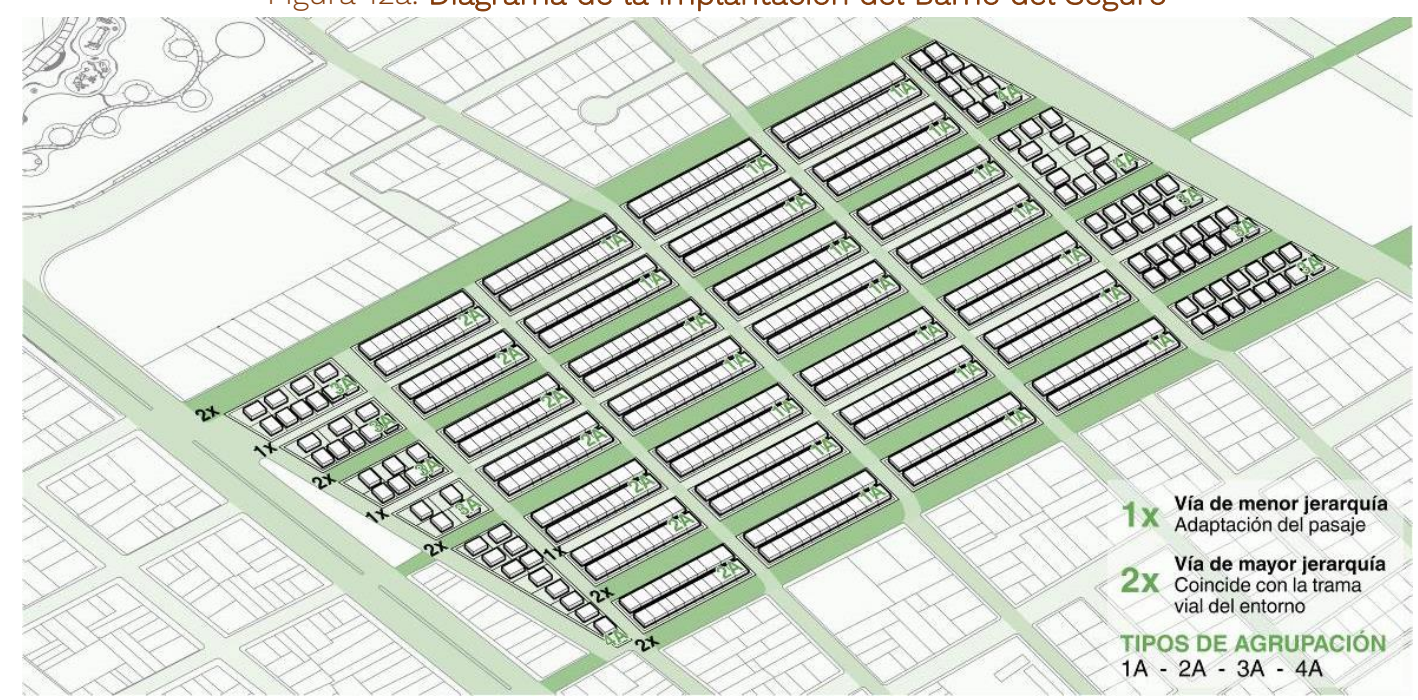

Fuente: Elaborado por el equipo de investigación, 2020.

Figura 12b. Comparativa de la distribución interna de las tipologías de vivienda del Barrio del Seguro

$\mathbf{P}$

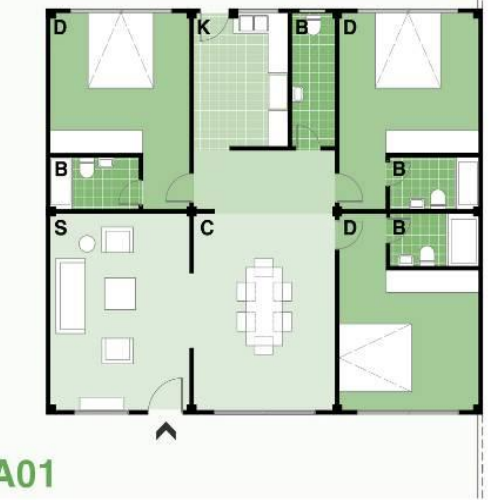

S Sala

C Comedor

K Cocina

D Dormitorio

B Baño

L Lavandería

P Patio
Tipología A01

VILLA PAREADA ESQUINERA Ubicada en las agrupaciones Tipo A1 y A2

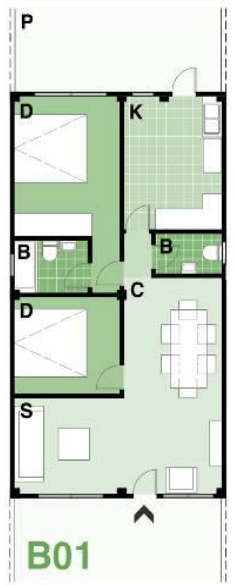

Tipología B01

VILLA ADOSADA

Ubicada en las agrupaciones

Tipo $A 1$ y $A 2$

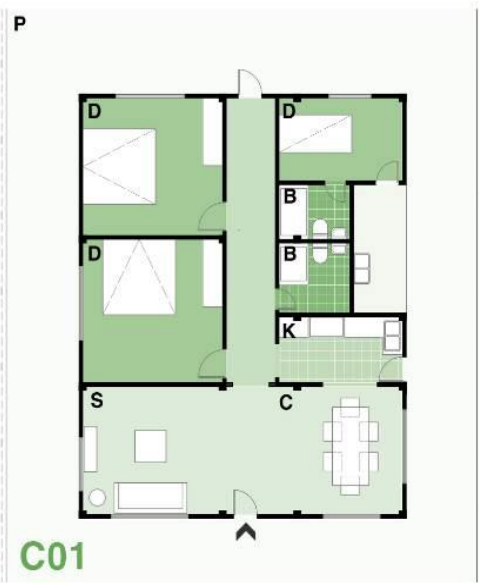

Tipología C01

VILLA AISLADA

Ubicada en las agrupaciones

Tipo A3 y A4

Fuente: Elaborado por el equipo de investigación, 2020. 
Las viviendas de las manzanas trapezoidales se implantan de diferentes formas dependiendo de la forma, tamaño y posición del lote dentro de la manzana. La vivienda se compone de tres crujías, dos mayores y una más reducida en el centro que es donde se ubica la distribución interior. Los espacios sociales se sitúan en el ingreso de la casa como preámbulo al área privada compuesta por los dormitorios y los espacios de servicio. El pasillo distribuidor divide la casa en una franja con dos dormitorios y otra en la que se ubican los baños, la cocina, la lavandería y una habitación de servicio. Estas viviendas, aunque también se desarrollan en una planta, presentan dimensiones mayores que los tipos adosados tanto en los espacios domésticos como en los jardines exteriores (Figura 12b).

\subsection{El Barrio Orellana: el último barrio de transición hacia la ciudadela}

El Barrio Orellana, denominado también Ciudadela Francisco de Orellana, constituye el último barrio obrero y un proyecto de transición hacia otras formas de entender las urbanizaciones de viviendas más segregadas y diferenciadas definidas por el modelo "ciudadela". El barrio presenta un tamaño considerable, similar al Barrio del Seguro, pero incorpora un nuevo instrumento de urbanización que son las diferentes fases y formas de ejecución de las viviendas a lo largo del tiempo.

El Barrio Orellana se sitúa, en el momento de su construcción, en una zona con apenas infraestructura y elementos notables del tejido urbano existente, por lo que debe resolver estos problemas de diversidad, variaciones y generación de identidades internas a escala de barrio. Los distintos tamaños y formas de manzanas vienen acompañados de diversos tipos de viviendas unifamiliares adosadas y separadas por retiros que alternan soluciones de cubierta plana e inclinada. Los reducidos retiros delanteros, protegidos por elementos de un metro de altura, hacen las veces de elemento de transición entre la calle y la vivienda (Figura 13a).

Figura 13a. Emplazamiento del Barrio Orellana por fases de ejecución de obras

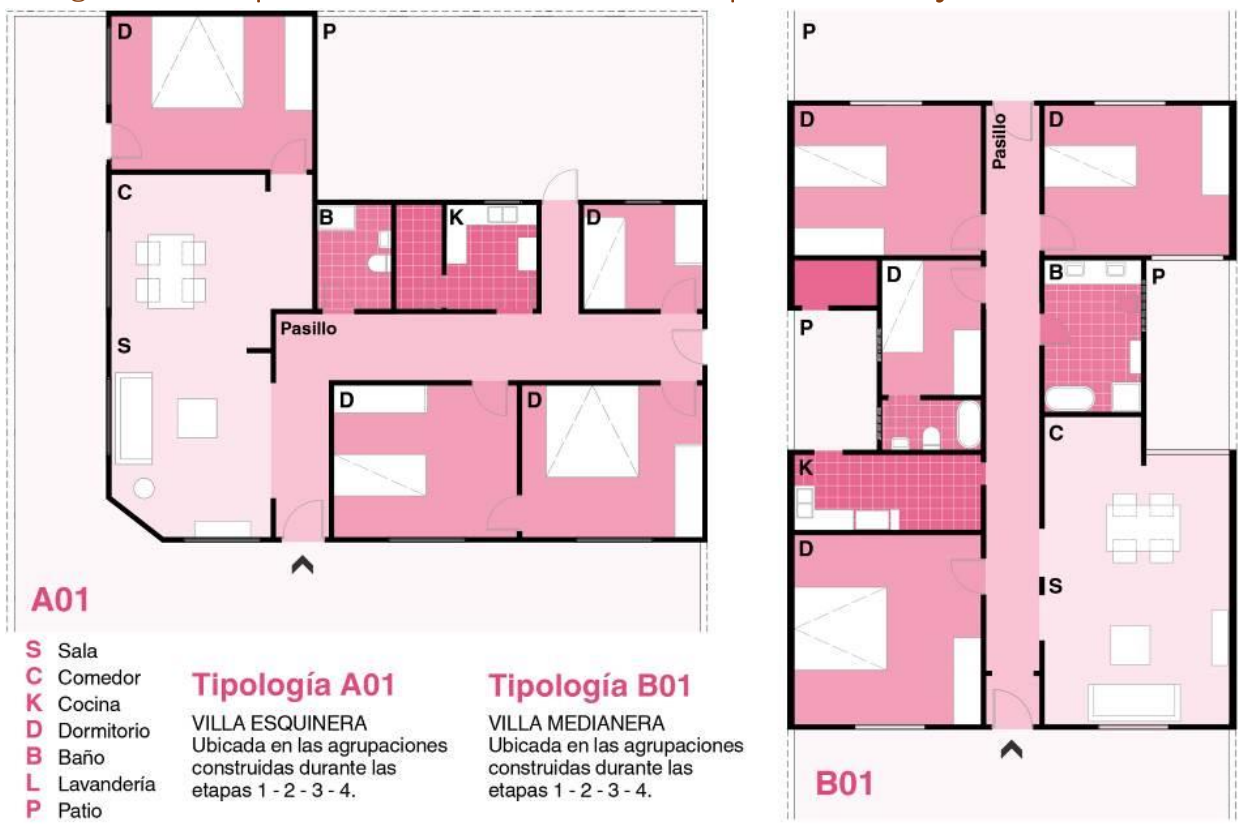

Fuente: Elaborado por el equipo de investigación, 2020.

ACE, 15 (4.5) CC BY-ND 3.0 ES | UPC Barcelona, España | Caracterización morfo-tipológica de los barrios obreros públicos en la ciudad de Guayaquil (1937-1948). DOI: http://dx.doi.org/10.5821/ace.15.45.9311 
Los tipos de vivienda del barrio son de una planta y están constituidos por la misma organización funcional: el ingreso a la vivienda se realiza directo al área social, y las áreas privadas, un poco dispersas alrededor de la misma, poseen patios interiores o aperturas hacia los retiros laterales o posteriores para la iluminación y ventilación de los diferentes ambientes. Formalmente solo varían los remates de las viviendas: unos tipos mantienen el remate plano y otros resaltan las cubiertas inclinadas (Figura 13b).

Figura 13b. Comparativa de la distribución interna de las tipologías de vivienda del Barrio Orellana

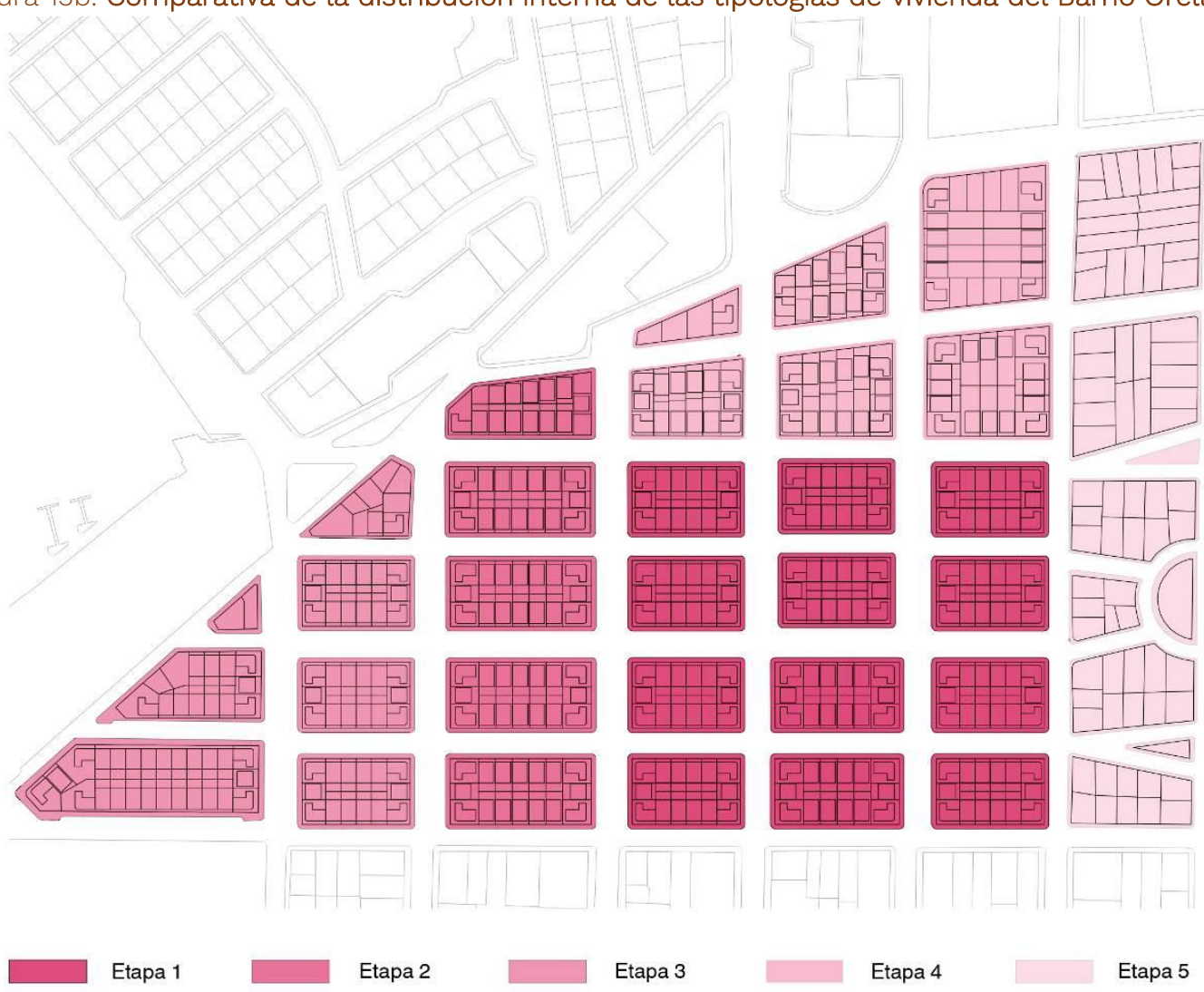

Fuente: Elaborado por el equipo de investigación, 2020.

La resolución de la esquina en forma de chaflán se convierte en un elemento distintivo de la manzana. Otra de las características que marca la diferencia con los proyectos anteriores es el aumento del ancho de las calzadas que favorecen un mayor tráfico vehicular en algunas vías compensado por la incorporación de otras de menor tránsito con aparcamientos y vegetación en las veredas. Se confirma la desaparición del pasaje, como ya había sucedido en el Barrio del Seguro, y su sustitución por una trama de vías secundarias de menor tráfico rodado que no poseen el carácter de calle peatonal capaz de generar una vida en comunidad a través de la transición progresiva entre lo público y lo privado que permite el soportal y el pasaje.

\section{Conclusiones}

El Gran Incendio constituye un punto de inflexión hacia una modernización revolucionaria sin ataduras historicistas. El proceso de modernización de Guayaquil se produce antes que, en Quito por una serie de condiciones específicas, entre otras, porque en Guayaquil se concentraba la

ACE, 15 (4.5) CC BY-ND 3.0 ES | UPC Barcelona, España | Caracterización morfo-tipológica de los barrios obreros públicos en la ciudad de Guayaquil (1937-1948). DOI: http://dx.doi.org/10.5821/ace.15.45.9311 
agroexportación cacaotera que posicionó a la ciudad como la más rica y poblada del país. Autores como Gutiérrez y Gutiérrez Viñuales (2012) han considerado que el peso de la arquitectura colonial en los países andinos como Perú, Bolivia o Ecuador impulsó el desarrollo de propuestas pintoresquistas y neocoloniales antes que modernas, por lo que el racionalismo no llegó sino tardíamente a ciudades como Quito (Compte, 2018). La arquitectura del habitar moderno en Guayaquil aparece como el encuentro forzado y discontinuado entre la tradición y el proyecto con la ineludible dificultad de relacionar estrechamente la domesticidad y la modernidad.

El problema de la vivienda de las clases populares que vienen del campo acelera la aparición en Guayaquil de una respuesta arquitectónica moderna bajo los principios de economía, durabilidad e higiene, dentro de una visión modernizadora de la sociedad emprendida por la Revolución Juliana a partir de 1925. Las características materiales de estos principios fueron la racionalización, la estandarización y la tipificación (Martín Hernández, 2014). Los casos analizados tratan de resolver el problema de organización de la vivienda mediante una arquitectura objetiva para un cliente anónimo como sucedió con la vivienda racional de la arquitectura moderna en Europa. Pero la diferencia sustancial entre la "vivienda mínima" de la clase trabajadora europea y la "vivienda para empleados" de las clases medias latinoamericanas es, por un lado, la creación de un programa de necesidades distinto en el que los estándares dimensionales aumentaron y. por otro, el régimen de propiedad que pasaba del alquiler a la posesión de una casa propia (Sambricio, 2012).

Se evidencia el fracaso de la planificación urbana municipal y el éxito de la producción de barrios como entidades independientes, pero no autosuficientes. El barrio se constituye en Guayaquil como el recinto primario de lo comunitario e identificador de las agrupaciones de familias de los mismos oficios o empresas. Los barrios objeto de estudio no pueden ser considerados como programas habitacionales sino como proyectos aislados, experiencias prácticas sin conexión en el sentido de una planificación.

La ausencia de planificación y de mecanismos legales de control del suelo conlleva la aparición en la periferia de la ciudad de dos fenómenos extremos: el surgimiento de urbanizaciones segregadas de las clases altas que huyen del centro histórico y el incremento de la informalidad y la vivienda autoproducida en terrenos anegadizos; este fenómeno responde a la indisoluble relación que existe entre la casa popular, la vivienda opulenta y la vivienda social (Ballent y Liernur, 2014).

La segregación socioespacial de los barrios en Guayaquil se manifiesta como una condición inherente desde el origen de la ciudad; no solo en el sentido de una separación social sino también, y fundamentalmente, física con límites naturales o construidos por el hombre. Los barrios obreros - especialmente el Pasaje 28 de Mayo y el Barrio del Seguro- tratan de romper con este fenómeno mediante estructuras que se integran al tejido existente y proveen de servicios y por tanto de cierta autosuficiencia a las familias que los habitan. Esta condición se va perdiendo desde el Barrio Orellana en favor del aislamiento que se instaura con el modelo de las "ciudadelas" como la Ciudadela Bolivariana-, y está estrechamente ligada con la desaparición de la calle como elemento de integración social.

Los elementos principales de la estructura parcelaria de la manzana de los casos de estudio son el pasaje como elemento estructurador de la manzana y espacio comunitario de referencia y los patios delanteros y traseros como dispositivos espaciales articuladores entre lo público y lo privado que sustituyen al soportal de la ciudad histórica. Las formas de parcelación de la manzana cuadrada a través del pasaje o mediante la incorporación de terrenos profundos, pero bien articulados en los lados secundarios son de gran valor como referencias para la reestructuración de las conflictivas y desorganizadas manzanas del centro histórico de Guayaquil.

ACE, 15 (4.5) CC BY-ND 3.0 ES | UPC Barcelona, España | Caracterización morfo-tipológica de los barrios obreros públicos en la ciudad de Guayaquil (1937-1948). DOI: $\underline{\text { http://dx.doi.org/10.5821/ace.15.45.9311 }}$ 
Se identifica una importante diversidad de tipos en los barrios que promueve la mezcla social; una de las premisas de los conjuntos es densificar y diversificar el tejido urbano con condiciones higiénicas y de confort: vivir próximos pero separados, compartir ciertas cosas, pero con ventajas individuales. Las soluciones formales se presentan como experiencias aisladas más cercanas a la experimentación que a una evolución lógica de las formas urbanas y los tipos edificatorios. Las diferentes formas y tipos difícilmente pueden clasificarse bajo modelos ortodoxos sino más bien como prácticas heterodoxas que suscitan la mezcla de técnicas y lenguajes.

Lo que tienen en común los proyectos estudiados es que, como la arquitectura moderna, pretendían cambiar la sociedad, y en este sentido, uno de los factores fundamentales del cambio vino a través de lo doméstico. La optimización e higiene del espacio doméstico, la constitución de un espacio privado e íntimo para cada familia, la estandarización y racionalización de los componentes de construcción y la integración entre el interior y el exterior son las verdaderas acciones revolucionarias que deben ser puestas en valor en la actualidad, no solo como patrimonio cultural, sino también como prácticas arquitectónicas y urbanas contemporáneas de primer orden.

\section{Agradecimientos}

Agradecemos a todos los ayudantes del equipo de investigación por su esfuerzo en el levantamiento de información, al Sistema de Investigación y Desarrollo (SINDE) de la Universidad Católica de Santiago de Guayaquil por el financiamiento de esta investigación y al Instituto de Investigación e Innovación en Hábitat, Diseño y Construcciones por su apoyo incondicional representado sobre todo por Teresa Pérez de Murzi y Tanya Donoso.

\section{Autoría}

El primero y segundo autor han conceptualizado y diseñado la investigación y la tercera autora junto al primero han desarrollado el análisis gráfico y textual de los casos de estudio.

Conflicto de intereses: Los autores declaran que no hay conflicto de intereses.

\section{Bibliografía}

Acta del Consejo de Guayaquil del 29 de octubre de 1937.

Aguirre, R. (1984). Estado y Vivienda en Guayaquil. Quito, Ecuador: FLACSO Ecuador.

Alcivar, M.; Lee, P.; Luque, S.; Rojas, M.; Valdivieso, F. (1980). Arquitectura Guayaquil 1930-1960. Análisis de la Producción Arquitectónica en Guayaquil, décadas del 30 al 50. Guayaquil: Tesis de Grado, Universidad Católica de Santiago de Guayaquil.

Almandoz, A. (2013). Modernización urbana en América Latina. De las grandes aldeas a las metrópolis masificadas. Santiago, Chile: Colección Estudios Urbanos UC.

Avilés, E.; Hoyos, M. (2007). El libro de Guayaquil: Siglo XX. Guayaquil, Ecuador: Poligráfica.

ACE, 15 (4.5) CC BY-ND 3.0 ES | UPC Barcelona, España | Caracterización morfo-tipológica de los barrios obreros públicos en la ciudad de Guayaquil (1937-1948). DOI: http://dx.doi.org/10.5821/ace.15.45.9311 
Aymonino, C. (1973). La vivienda racional. Ponencias de los congresos CIAM 1929-1930. Barcelona, españa: Gustavo Gili.

Ballent, A.; Liernur, J. F. (2014). La casa y la multitud. Vivienda, política y cultura en la Argentina moderna. Buenos Aires, Argentina: Fondo de Cultura Económica.

Bock, S. (1992). Guayaquil. Arquitectura, espacio y sociedad, 1900-1940. Quito, Ecuador: Corporación Editora Nacional.

Chadwick, E. (1843). Report on the sanitary condition of the laboring population of Great Britain. Londres, reino Unido: W. Clowes and Sons.

Compte, F. (2018). Arquitectura moderna de Guayaquil 1930-1948. Guayaquil, Ecuador: Dirección de Publicaciones de la UCSG.

Compte, F. (2020). La producción arquitectónica de Francesco Maccaferri y su relación con los cambios en la arquitectura de Guayaquil 1923-1942. Guayaquil, Ecuador: Universidad Católica de Santiago de Guayaquil.

Cueva, A. (1973). El proceso de dominación política en el Ecuador. Quito, Ecuador: Solitierra.

Engels, F. (2019). Contribución al problema de la vivienda. Madrid: Libros Corrientes (Publicado por primera vez en el periódico Volkstaat, 1872).

Estrada Ycaza, J. (2000). Guía histórica de Guayaquil. Tomo 3, D-G. Guayaquil, Ecuador: Poligráfica.

Evans, R. (2005) Traducciones. Girona, España: Pre-Textos de Arquitectura, COAC (1… ed. Ing., 1997).

Gilbert, A. (1997). La ciudad latinoamericana. México: Siglo XXI Editores.

Gutiérrez, R.; Tartarini, J.; Stagno, R. (2007). Congresos Panamericanos de arquitectos 1920-2000. Aportes para su historia. Buenos Aires, Argentina: CEDODAL.

Gutiérrez, R., Gutiérrez Viñuales, R. (2012). Una mirada crítica a la arquitectura latinoamericana del Siglo XX. De las realidades a los desafios. En E. K. (ed.), 1810-1910-2010. Independencias dependientes. Art and national identities in Latin America. Dresde, Alemania: Universidad de Dresde.

Harvey, D. (1990). La condición de la posmodernidad. Investigaciones sobre los orígenes del cambio cultural. Buenos Aires, Argentina: Amorrortu Editores.

Lee, P.; Compte, F.; Antonieta, A. (1987). Patrimonio arquitectónico y urbano de Guayaquil. Siglo XIX1950. Proyecto de investigación. Guayaquil, Ecuador: Universidad Católica de Santiago de Guayaquil.

Lee, P.; Compte, F. (1992). Guayaquil: Lectura histórica de la ciudad. Guayaquil, Ecuador: Universidad Católica de Santiago de Guayaquil.

ACE, 15 (4.5) CC BY-ND 3.0 ES | UPC Barcelona, España | Caracterización morfo-tipológica de los barrios obreros públicos en la ciudad de Guayaquil (1937-1948). DOI: http://dx.doi.org/10.5821/ace.15.45.9311 
Lee, P.; Compte, F.; Peralta, C. (1996). Testimonio y memoria de la arquitectura histórica de Guayaquil. Guayaquil, Ecuador: Artes gráficas SENEFELDER.

Martín Hernández, M. (2014). La casa en la arquitectura moderna. Respuestas a la cuestión de la vivienda. Barcelona, España: Editorial Reverté.

Panerai, P. (1986). Formas urbanas: de la manzana al bloque. Barcelona, España: Gustavo Gili.

Panerai, P.; Mangin, D. (2002). Proyectar la ciudad. Madrid, España: Celeste Ediciones.

Paz y Miño Cepeda, J. (2013). La Revolución Juliana en Ecuador (1925-1931). Políticas económicas. Quito, Ecuador: Ministerio Coordinador de Política Económica.

Pradilla, E. (1983). El problema de la vivienda en América Latina. Quito, Ecuador: Centro de Investigaciones CIUDAD.

Rojas, M.; Villavicencio, G. (1988). El proceso urbano de Guayaquil 1870-1980. Guayaquil, Ecuador: ILDIS CER-G.

Rojas, M. (2019). El proceso urbano de Guayaquil: Del Espacio portuario a la metrópoli. Guayaquil, Ecuador: Universidad Católica de Santiago de Guayaquil.

Romero, J.L. (2010). Latinoamérica: las ciudades y las ideas. Buenos Aires, Argentina: Siglo XXI Editores Argentina.

Sambricio, C. (Ed.). (2012). Ciudad y vivienda en América Latina 1930-1960. Madrid, España: Lampreave.

Sánchez Bravo, M. (23 de abril de 2017). La Grace Line. El Expreso. Memorias Porteñas. Recuperado de https://www.pressreader.com/

Sánchez, P. (2015). Mercado de suelo informal y políticas de hábitat urbano en la ciudad de Guayaquil. Quito, Ecuador: FLACSO Ecuador.

Sinardet, E. (1999). La preocupación higienista en la educación ecuatoriana en los años treinta y cuarenta. Lima, parú: Bulletin Institut Français d’Études Andines, pp. 411-432.

Solano, A.; Villacrés, C. (2011). Categorización y definición Socio espacial del barrio como unidad básica territorial para el desarrollo urbano: Los Barrios en Guayaquil. Guayaquil, Ecuador: Universidad Católica de Santiago de Guayaquil. 